\title{
Research Article \\ Dopaminergic Suppression of Synaptic Transmission in the Lateral Entorhinal Cortex
}

\author{
Douglas A. Caruana and C. Andrew Chapman \\ Center for Studies in Behavioral Neurobiology, Department of Psychology, Concordia University, Montréal, \\ Québec, Canada H4B 1R6 \\ Correspondence should be addressed to C. Andrew Chapman, andrew.chapman@concordia.ca
}

Received 29 March 2008; Accepted 21 June 2008

Recommended by Roland S. G. Jones

\begin{abstract}
Dopaminergic projections to the superficial layers of the lateral entorhinal cortex can modulate the strength of olfactory inputs to the region. We have found that low concentrations of dopamine facilitate field EPSPs in the entorhinal cortex, and that higher concentrations of dopamine suppress synaptic responses. Here, we have used whole-cell current clamp recordings from layer II neurons to determine the mechanisms of the suppression. Dopamine (10 to $50 \mu \mathrm{M}$ ) hyperpolarized membrane potential and reversibly suppressed the amplitude of EPSPs evoked by layer I stimulation. Both AMPA- and NMDA-mediated components were suppressed, and paired-pulse facilitation was also enhanced indicating that the suppression is mediated largely by reduced glutamate release. Blockade of $\mathrm{D}_{2}$-like receptors greatly reduced the suppression of EPSPs. Dopamine also lowered input resistance, and reduced the number of action potentials evoked by depolarizing current steps. The drop in input resistance was mediated by activation of $\mathrm{D}_{1}$-like receptors, and was prevented by blocking $\mathrm{K}^{+}$channels with TEA. The dopaminergic suppression of synaptic transmission is therefore mediated by a $\mathrm{D}_{2}$ receptor-dependent reduction in transmitter release, and a $\mathrm{D}_{1}$ receptor-dependent increase in a $\mathrm{K}^{+}$conductance. This suppression of EPSPs may dampen the strength of sensory inputs during periods of elevated mesocortical dopamine activity.
\end{abstract}

Copyright (c) 2008 D. A. Caruana and C. A. Chapman. This is an open access article distributed under the Creative Commons Attribution License, which permits unrestricted use, distribution, and reproduction in any medium, provided the original work is properly cited.

\section{INTRODUCTION}

The entorhinal cortex is animportant interface that links primary sensory and association cortices to the hippocampal formation, and it is critical for the sensory and mnemonic functions of the medial temporal lobe [1-4]. In the rat, the lateral division of the entorhinal cortex receives most of its cortical inputs from the olfactory cortex and perirhinal cortex, and the medial entorhinal cortex receives visual and multimodal inputs mainly via the postrhinal cortex [5-7]. This pattern of cortical input to the medial and lateral divisions of the entorhinal cortex contributes to their different roles in sensory and cognitive processing [8-10]. In addition, neuromodulatory transmitters innervate both the medial and lateral entorhinal cortices and can have powerful effects on sensory and mnemonic function in these regions. Specifically, acetylcholine and serotonin both modulate synaptic transmission and rhythmic EEG activities in the medial entorhinal cortex [11-15]. Further, midbrain dopamine neurons send one of their largest cortical projections to the superficial layers of the lateral entorhinal cortex where they target principal cell islands [16-18]. Relatively little is known, however, regarding the neuromodulatory effects of dopamine in the lateral entorhinal cortex.

The large dopaminergic projection to the prefrontal cortex is known to regulate cellular processes related to working memory [19-21], and dopaminergic inputs to the lateral entorhinal cortex are also likely to affect mechanisms of sensory and mnemonic function. In the prefrontal cortex, activation of $\mathrm{D}_{1}$ receptors can suppress glutamate release in layer $\mathrm{V}$ [22-24] but can enhance glutamatergic transmission in layer III $[25,26]$. Further, the positive effect of $D_{1}$ receptor activation on working memory follows an inverted Ushaped function [27], and strong or weak stimulation of $\mathrm{D}_{1}$ receptors can also have opposite effects on NMDA receptormediated synaptic currents $[20,28]$. We have also found that 
dopamine has dose-dependent bidirectional effects in layer II of the lateral entorhinal cortex. In awake animals, increasing levels of dopamine with a selective reuptake inhibitor facilitates synaptic responses evoked by stimulation of the piriform cortex, and field excitatory postsynaptic potentials (fEPSPs) are also facilitated by a low concentration of dopamine in vitro [29]. Higher concentrations of dopamine, however, suppress fEPSPs, and similar suppression effects have been observed by others in medial entorhinal cortex layer II [30] and layer III [31]. Dopamine can also reduce the input resistance of layer IIneurons in the medial entorhinal cortex [30] and reduce temporal summation in layer $\mathrm{V}$ neurons of the lateral division through an increase in the $I_{\mathrm{h}}$ current [32]. Dopamine may therefore modulate synaptic function in the lateral entorhinal cortex through multiple mechanisms.

We have used whole-cell current clamp recordings to investigate the mechanisms of the suppression of EPSPs by dopamine in electrophysiologically identified "fan" cells in layer II of the lateral entorhinal cortex. Receptor blockers were used to determine the dopamine receptors that mediate the suppression of EPSPs, and paired-pulse tests were used to assess whether the suppression is expressed pre- or postsynaptically. Changes in the intrinsic excitability of fan cells were also monitored using responses to hyperpolarizing and depolarizing current steps. In addition to a $\mathrm{D}_{2}$ like receptor-mediated suppression of transmitter release, we show evidence that EPSPs are also reduced by an increased $\mathrm{K}^{+}$conductance dependent on activation of $\mathrm{D}_{1}$ receptors.

\section{MATERIALS AND METHODS}

\subsection{Tissue slices}

Methods for obtaining whole cell current clamp recordings were similar to those described previously [13, 29, 33, 34]. Male Long-Evans rats between 4 and 6 weeks old were anesthetized with halothane, decapitated, and their brains rapidly removed and transferred into cold $\left(4^{\circ} \mathrm{C}\right)$ artificial cerebrospinal fluid (ACSF) saturated with $95 \% \mathrm{O}_{2}$ and $5 \%$ $\mathrm{CO}_{2}$ containing (in $\mathrm{mM}$ ) $124 \mathrm{NaCl}, 5 \mathrm{KCl}, 1.25 \mathrm{NaH}_{2} \mathrm{PO}_{4}$, $2 \mathrm{MgSO}_{4}, 2 \mathrm{CaCl}_{2}, 26 \mathrm{NaHCO}_{3}$, and10 dextrose $(\mathrm{pH}$ $\approx 7.3$; 300-310 mOsm). All chemicals were obtained from Sigma-Aldrich, Mo, USA. Horizontal slices (300 $\mu \mathrm{m}$ thick) were cut using a vibratome (WPI, Vibroslice, Fla, USA), and slices recovered for at least one hour at 22 to $24^{\circ} \mathrm{C}$. Slices were transferred individually to a recording chamber and visualized using an upright microscope (Leica, Richmond Hill, Canada, DM-LFS) equipped with differential interference contrast optics, a 40x water immersion objective, and a near-infrared camera (COHU, Inc., Calif, USA). Submerged slices were superfused with oxygenated ACSF at a rate of 1.5 to $2.0 \mathrm{~mL} / \mathrm{min}$. Slices containing the lateral entorhinal cortex were taken from ventral sections about 1.9 to $3.4 \mathrm{~mm}$ above the interaural line [35]. Layer IIwas identified based on the presence of cell "islands" about $150 \mu \mathrm{m}$ from the cortical surface [36-39].

\subsection{Stimulation and recording}

Patch recording pipettes for whole cell recordings were prepared from borosilicate glass $(1.0 \mathrm{~mm} \mathrm{OD,} 4$ to $8 \mathrm{M} \Omega$ ) using a horizontal puller (P-97, Sutter Instr., Calif, USA) and were filled with a solution containing (in $\mathrm{mM}$ ) 140 K-gluconate, $5 \mathrm{NaCl}, 2 \mathrm{MgCl}_{2}, 10 \mathrm{HEPES}, 0.5$ EGTA, 2 ATP-Tris, and 0.4 GTP-Tris ( $\mathrm{pH}$ adjusted to 7.24-7.32 with $\mathrm{KOH} ; 270-280 \mathrm{mOsm}$ ). Pipettes were placed in contact with somata of layer II neurons, and gentle suction was applied under voltage clamp to form a tight seal (1-3G $\Omega$ ). Whole cell configuration was achieved by increased suction, and experiments began after cells stabilized (typically within 3 to 5 minutes after break-in). Current clamp recordings were obtained using an Axopatch 200B amplifier (Axon Instr., Calif, USA) and displayed on a digital oscilloscope (Gould 1604). Recordings were filtered at $10 \mathrm{kHz}$ and digitized at $20 \mathrm{kHz}$ (Axon Instr., Digidata 1322A) for storage on computer hard disk. Recordings were accepted if the series resistance was $\leq 25 \mathrm{M} \Omega($ mean $=16.9 \pm 0.9 \mathrm{M} \Omega$ ) and if input resistance and resting potential were stable. A bipolar stimulating electrode made from two tungsten electrodes (FHC, 1.0 M $\Omega$ ) was positioned to span layer I near the border with layer II approximately 0.2 to $0.6 \mathrm{~mm}$ rostral to the recording electrode. Synaptic responses were evoked with 0.1 millisecond constant current pulses delivered using a stimulus timer and isolation unit (WPI, Mass, USA, models A300 and A360). Stimulation intensity was adjusted to evoke responses approximately $75 \%$ of maximal ( 75 to $300 \mu \mathrm{A})$.

All neurons $(n=118)$ included for analyses were identified as "fan" cells based on electrophysiological characteristics described previously $[40,41]$. In comparison tostellate cells of the medial entorhinal cortex, fan cells show modest inward rectification during hyperpolarizing current steps, a small depolarizing afterpotential following single spikes, and do not show prominent theta-frequency membrane potential oscillations at subthreshold voltages [40-42].

\subsection{Dopaminergic modulation of synaptic responses}

The effects of dopamine on glutamate-mediated synaptic transmission in the lateral entorhinal cortex are largely uncharacterized. We therefore recorded both mixed and isolated components of excitatory postsynaptic potentials (EPSPs) evoked by stimulation of layer I before and after 5 -minute bath-application of 1,10 , or $50 \mu \mathrm{M}$ dopamine. Results obtained using high concentrations of dopamine must be interpreted cautiously because of the possibility of nonspecific effects. However, dopamine degrades through oxidization within the slice preparation, and similar concentrations of dopamine have been used previously, and interpreted in light of the effects of specific antagonists, in reports examining the effects of dopamine on synaptic transmission in both the entorhinal [29-32] and prefrontal $[23,43]$ cortices. Responses were evoked once every 20 seconds, and the mean of 10 responses was obtained for analysis. Baseline responses were obtained at resting potential and, because dopamine usually hyperpolarizes fan cells, constant current was often required to return cells 
to the original membrane potential for recordings in the presence of dopamine. Sodium metabisulfite $(50 \mu \mathrm{M})$ was coapplied to slow the oxidation of dopamine $[29,31,43]$, and ambient lighting was also reduced. Possible effects of sodium metabisulfite were assessed with a vehicle control group. Drugs were routinely stored at $-20^{\circ} \mathrm{C}$ as concentrated stock solutions until needed, but dopamine $\mathrm{HCl}$ was dissolved just prior to bath application.

Paired-pulse tests were used to determine whether dopamine modulates EPSPs through a pre- or postsynaptic mechanism [13]. Pairs of stimulation pulses separated by an interval of 30 milliseconds were delivered before and after 5-minute bath-application of 1,10 , or $50 \mu \mathrm{M}$ dopamine. Stimulation intensity was reduced to evoke EPSPs approximately $50 \%$ of maximal, and ten responses were averaged for analyses. Paired-pulse facilitation was quantified by expressing the amplitude of the second response as a percentage of the first response.

Mechanisms mediating the suppression of EPSPs by high concentrations of dopamine were investigated by assessing the effects of $50 \mu \mathrm{M}$ dopamine on isolated components of synaptic responses. After baseline recordings in normal ACSF, AMPA receptor-mediated responses were isolated with bath application of $50 \mu \mathrm{M}$ 2-amino-5-phosphonovaleric acid (APV) and $25 \mu \mathrm{M}$ bicuculline methiodide, or NMDA receptor-mediated responses were isolated with $20 \mu \mathrm{M}$ 7-nitro-2,3-dioxo-1,4-dihydroquinoxaline-6-carbonitrile (CNQX) and $25 \mu \mathrm{M}$ bicuculline. GABA-mediated IPSPs were isolated with either $1 \mathrm{mM}$ kynurenic acid or $20 \mu \mathrm{M}$ CNQX with $50 \mu \mathrm{M}$ APV. Isolated synaptic responses were recorded before and after 5-minute application of $50 \mu \mathrm{M}$ dopamine. Isolated AMPA receptor-mediated responses were also used to determine if dopamine suppresses EPSPs primarily through $\mathrm{D}_{1}$ - or $\mathrm{D}_{2}$-like receptors. Baseline responses were recorded in the presence of either the $\mathrm{D}_{1}$ receptor antagonist SCH23390 $(50 \mu \mathrm{M})$ or the $\mathrm{D}_{2}$ receptor antagonist sulpiride $(50 \mu \mathrm{M})$ [29-31], and $50 \mu \mathrm{M}$ dopamine was then applied for 5 minutes. Sulpiride was prepared daily in a stock solution of $6 \%$ DMSO in ACSF titrated with $0.1 \mathrm{~N} \mathrm{HCl}$, and there was a final concentration of $0.1 \%$ DMSO with sulpiride.

The effects of dopamine on the intrinsic excitability of fan cells were assessed by monitoring responses to hyperpolarizing and depolarizing current steps. Changes in action potentials, afterhyperpolarizations, input resistance and inward rectification were examined before and after 5 -minute bath application of 1,10 , or $50 \mu \mathrm{M}$ dopamine. The number of action potentials elicited in response to suprathreshold current injection can be used to characterize neuronal excitability [32], and we therefore determined the number of spikes fired in response to a single 500 millisecond-duration depolarizing current pulse from a constant holding potential (typically rest) using a pulse amplitude that elicited 3 to 5 action potentials [32]. Receptors that mediate the dopamine-induced change in input resistance were investigated using SCH23390 or sulpiride, and the ionic conductances involved were assessed using $0.5 \mu \mathrm{M}$ tetrodotoxin (TTX) or $30 \mathrm{mM}$ tetraethylammonium (TEA). Blockers were preapplied for 5-10 minutes prior to coapplication of dopamine for 5 minutes.

\subsection{Data analysis}

Electrophysiological characteristics of fan cells and changes in synaptic responses were analyzed using the software program Clampfit 8.2 (Axon Instr., Calif, USA). The amplitudes of averaged EPSPs were measured relative to the prestimulus baseline, and paired-pulse facilitation was determined by expressing the amplitude of the second response as a proportion of the amplitude of the first response. Action potential amplitude was measured from resting potential, and action potential width and fast and medium afterhyperpolarizations were measured from threshold. Input resistance was calculated by measuring peak and steady-state voltage responses to $-200 \mathrm{pA}$ current steps (500 milliseconds), and inward rectification was quantified by expressing the peak input resistance as a proportion of the steady-state resistance (rectification ratio). All data were expressed as the mean \pm SEM for plotting, and changes in response properties were assessed using paired samples $t$ tests or mixed design ANOVAs.

\section{RESULTS}

\subsection{Electroresponsiveness of layer II fan cells}

A total of 118 fan cells in layer II of the lateral entorhinal cortex were identified electrophysiologically and included for analysis, and the characteristics of these cells were similar to those reported previously $[40,41]$. Fan cells had a mean resting membrane potential of $-58.8 \pm 0.6 \mathrm{mV}$, and a peak input resistance of $99.1 \pm 2.1 \mathrm{M} \Omega$. Most cells (108 of 118) demonstrated a small delayed inward rectification in response to hyperpolarizing current steps (rectification ratio: $1.10 \pm 0.01$ ). Action potentials (amplitude: $128.8 \pm$ $0.7 \mathrm{mV}$, width: $4.1 \pm 0.1$ milliseconds, threshold: $-44.1 \pm$ $0.8 \mathrm{mV}$ ) were typically followed by fast and medium afterhyperpolarizations $(-3.3 \pm 0.3 \mathrm{mV}$ and $-5.8 \pm 0.3 \mathrm{mV})$ with a small depolarizing afterpotential. Averaged EPSPs evoked by stimulation of layer I had a mean amplitude of $4.4 \pm 0.2 \mathrm{mV}$. Continuous recordings of membrane potential were obtained in a subset of 28 cells to assess subthreshold membrane potential oscillations and, similar to findings of Tahvildari and Alonso [40], fan cells did not display prominent oscillations (data not shown).

\subsection{Dopaminergic modulation of EPSPs}

We previously found concentration-dependent effects of dopamine on field EPSPs in layer II in vitro, in which $10 \mu \mathrm{M}$ dopamine facilitated fEPSPs and 50 to $100 \mu \mathrm{M}$ dopamine suppressed fEPSPs [29]. We obtained similar concentrationdependent effects in whole cell EPSPs recorded here before and after 5-minute bath application of dopamine. Application of $50 \mu \mathrm{M}$ dopamine resulted in a strong suppression of synaptic response to $38.5 \pm 5.8 \%$ of baseline levels (see Figure $\left.1(\mathrm{a}) ; t_{8}=7.75, P<.001 ; n=9\right)$ that could be reversed by 15 minutes washout in normal ACSF ( 3 cells). We initially expected $10 \mu \mathrm{M}$ dopamine to facilitate EPSPs [29], but foundthat $10 \mu \mathrm{M}$ dopamine instead caused a small synaptic suppression (to $87.0 \pm 5.8 \%$ of baseline; see Figure $1(\mathrm{~b}) ; t_{15}$ 


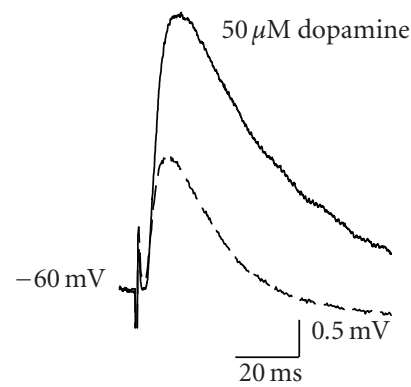

- ACSF

$--\mathrm{DA}$

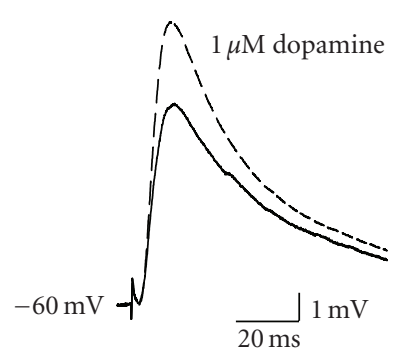

- ACSF

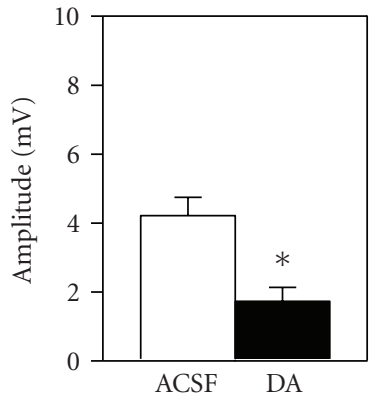

)

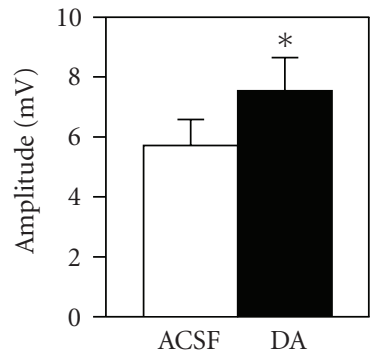

c)
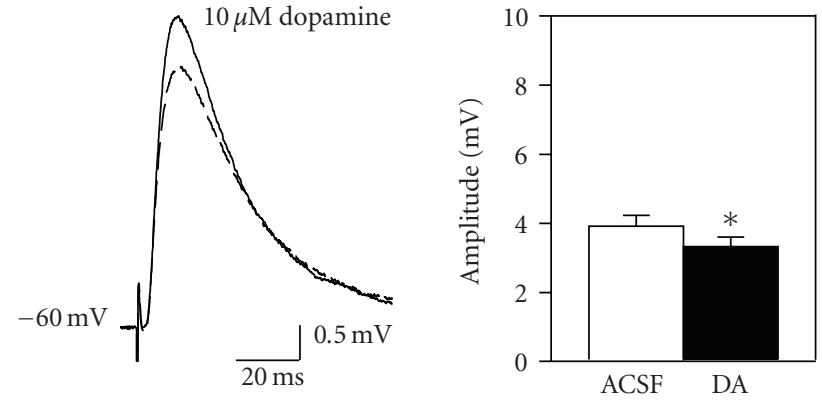

- ACSF

(b)
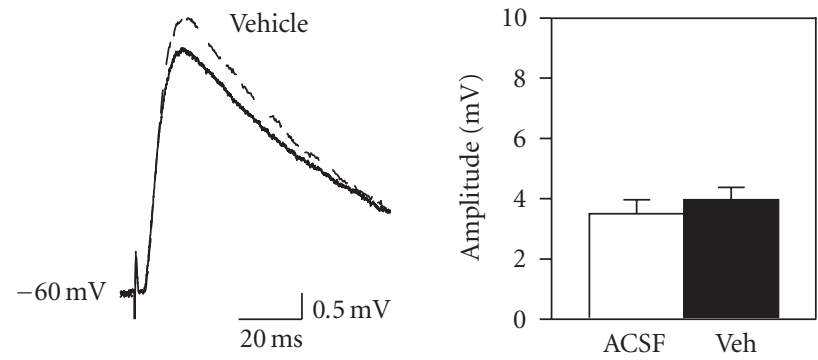

(d)

FIGURE 1: Dopamine has dose-dependent and bidirectional effects on the amplitude of mixed EPSPs in layer II fan cells. (a) Fifty $\mu \mathrm{M}$ dopamine significantly reduces the amplitude of synaptic responses. Traces show averaged EPSPs before (ACSF) and after 5-minute bath application of dopamine (DA) in a representative cell. Group data indicate the mean amplitude of EPSPs before and after dopamine $(*, P<$ .001 ). Bars indicate \pm 1 SEM in this and subsequent figures, and * indicates $P<.05$ unless otherwise indicated. (b) A lower concentration of $10 \mu \mathrm{M}$ dopamine causes a smaller suppression of synaptic responses. (c) The low $1 \mu \mathrm{M}$ concentration of dopamine enhances the amplitude of synaptic responses $(*, P<.01)$. (d) Bath application of vehicle $(50 \mu \mathrm{M}$ sodium metabisulfite; Veh $)$ does not significantly affect synaptic transmission.

$=2.31, P<.05 ; n=18)$. However, a lower concentration of $1 \mu \mathrm{M}$ dopamine significantly enhanced responses to $132.7 \pm$ $4.4 \%$ of baseline levels (see Figure $1(\mathrm{c}) ; t_{6}=5.04, P<.01 ; n=$ 7). In our previous study using a gas-fluid interface chamber, a larger bath volume and slower flow-rate may have increased dopamine oxidation and reduced the effective concentration of dopamine at the slice, and this may account for why a higher applied concentration facilitated responses in that study [29]. Bath application of the antioxidant sodium metabisulfite alone had no significant effect on the amplitude of whole cell EPSPs (see Figure 1(d); $n=8$ ).

Paired-pulse tests were used to determine if synaptic suppression and facilitation effects were likely expressed preor postsynaptically. Pairs of pulses were delivered before and after 5-minute dopamine application, and a 30-millisecond interpulse interval was used that results in optimal pairedpulse facilitation [13, 44-46]. If EPSPs are reduced through a reduction in transmitter release, then a greater amount of transmitter should be available for release in response to the second stimulation pulse and paired-pulse facilitation should be enhanced [47-49]. Changes in EPSPs mediated by alterations in postsynaptic receptors, however, should not be associated with changes in paired-pulse ratio. High concentrations of dopamine that reduced EPSP amplitude were also found to enhance paired-pulse facilitation (see Figures $2(\mathrm{a}), 2(\mathrm{~b}) ; t_{13}=2.78, P<.05$ for $10 \mu \mathrm{M}$; $t_{8}=$ 2.97, $P<.05$ for $50 \mu \mathrm{M}$ ), suggesting that dopamine reduced EPSPs by suppressing glutamate release. In contrast, the low concentration of $1 \mu \mathrm{M}$ dopamine that facilitated EPSPs had no significant effect on paired pulse facilitation (see Figure 2(c)), suggesting that the facilitation of EPSPs was mediated primarily by an increased postsynaptic response to glutamate. The dopaminergic facilitation of the conditioning response was smaller during paired-pulse tests in which stimulus intensity was reduced to avoid spiking (see Figures 1(c) versus 2(c)) but a similar dopaminergic facilitation of fEPSPs with no effect on paired-pulse ratio has been observed in the entorhinal cortex in vivo [29].

\subsection{Isolated synaptic responses}

The suppression of EPSPs by high concentrations of dopamine was examined more closely using pharmacologically isolated synaptic responses. Consistent with a 


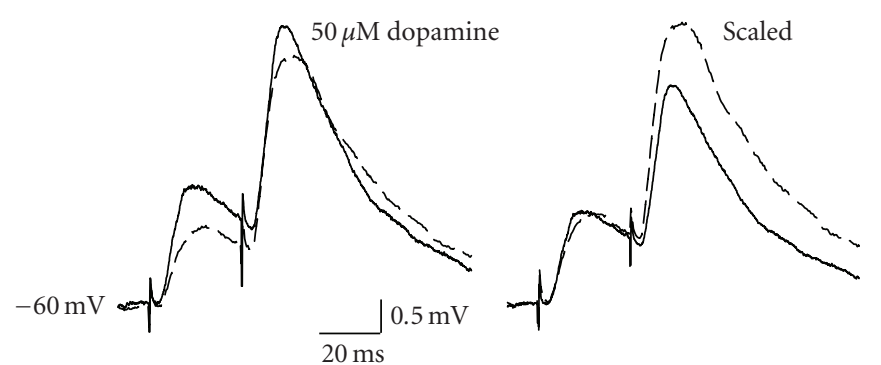

(a)
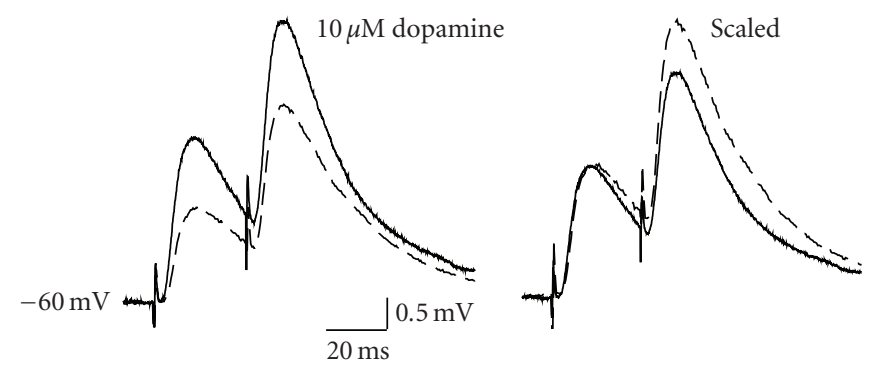

(b)

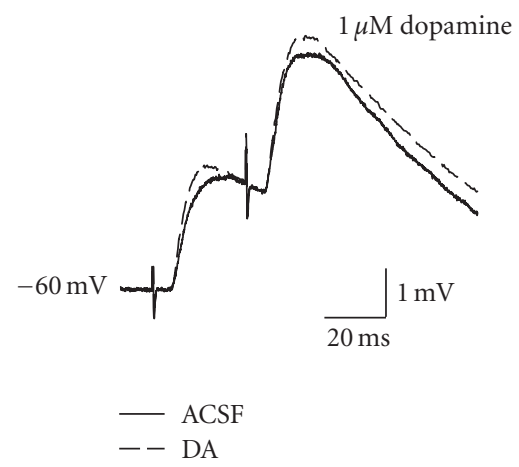

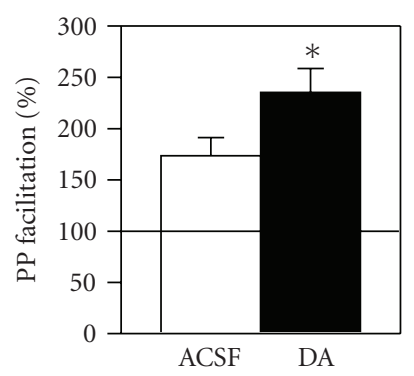
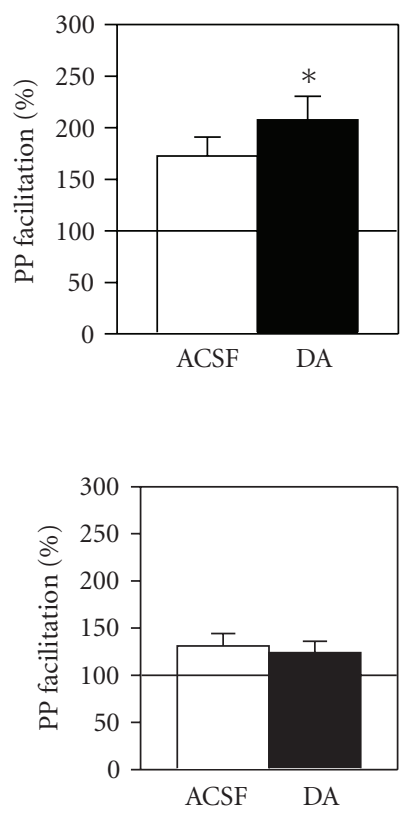

(c)

FIGURE 2: High concentrations of dopamine increase paired-pulse facilitation. (a) Pairs of stimulation pulses with a 30 millisecond interpulse interval were delivered before and after 5-minute bath application of $50 \mu \mathrm{M}$ dopamine. Averaged traces at left show responses recorded before (ACSF) and after (DA) dopamine from a representative cell. Note the suppression of the response to the first pulse and the large facilitation of the second response following dopamine (dotted line). Traces at right have been scaled to the amplitude of the first response in normal ACSF to aid comparison. Group data are shown on the right. (b) Paired-pulse facilitation was also enhanced by $10 \mu \mathrm{M}$ dopamine. (c) In contrast, the low concentration of $1 \mu \mathrm{M}$ dopamine does not affect paired-pulse ratio.

suppression of glutamate release from presynaptic terminals, bath application of $50 \mu \mathrm{M}$ dopamine significantly attenuated both the isolated AMPA- and NMDA-mediated responses. The NMDA component was reduced to $26.0 \pm 7.5 \%$ of baseline (see Figure 3(b); $t_{7}=3.32, P<.05 ; n=8$ ) and the AMPA component was reduced to $41.7 \pm 5.6 \%$ of baseline (see Figure $3(\mathrm{a}) ; t_{5}=3.50, P<.05 ; n=$ 6).

Dopamine receptor subtypes underlying the suppression of AMPA-mediated synaptic responses were investigated by applying $50 \mu \mathrm{M}$ dopamine in the presence of either the $\mathrm{D}_{1}$ receptor antagonist $\mathrm{SCH} 23390(50 \mu \mathrm{M})$ or the $\mathrm{D}_{2}$ receptor antagonist sulpiride $(50 \mu \mathrm{M})$. Similar to previous reports that have used selective agonists in the medial $[30,31]$ and lateral [29] entorhinal cortex, application of either the $D_{1}$ agonist SKF38393 (25 to $50 \mu \mathrm{M} ; n=9$ ) or the $\mathrm{D}_{2}$ agonist quinpirole (20 to $40 \mu \mathrm{M} ; n=10$ ) had no effect on EPSPs (data not shown), and we therefore used receptor blockers known to affect synaptic responses in the lateral entorhinal cortex [29]. Application of antagonists alone had no effect on EPSPs, and the $\mathrm{D}_{1}$ antagonist SCH23390 did not block the suppression of AMPA-mediated EPSPs (see Figure 4(a); $t_{4}=3.0, P<.05 ; n=5$ ), suggesting that $\mathrm{D}_{1}$ receptors do not mediate the suppression. However, blockade of $\mathrm{D}_{2}$ receptors with sulpiride significantly reduced the effects of dopamine on AMPA-mediated EPSPs. Coapplication of dopamine with sulpiride $(n=5)$ resulted in a nonsignificant suppression of synaptic responses, and the size of the suppression was significantly smaller than that observed with dopamine alone $\left(79.8 \pm 7.2 \%\right.$ versus $41.7 \pm 5.6 \%$ of baseline; $F_{1,9}=18.10$, 

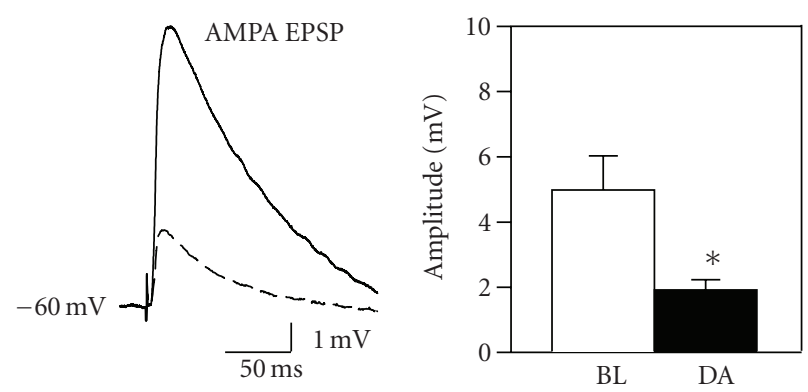

$-\mathrm{BL}$

(a)
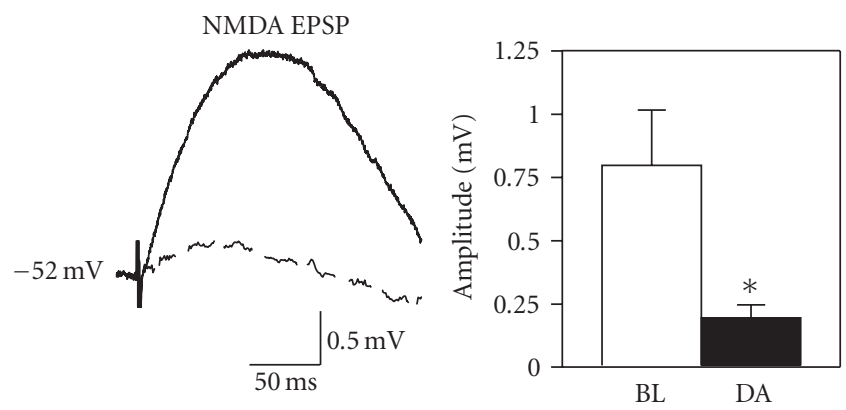

$-\mathrm{BL}$

(b)

Figure 3: Dopamine suppresses the amplitude of both AMPAand NMDA receptor-mediated components of EPSPs. (a) AMPAmediated EPSPs recorded in the presence of APV and bicuculline were suppressed by $50 \mu \mathrm{M}$ dopamine. Averaged traces show EPSPs recorded before (BL) and after (DA) dopamine application, and group data are shown at right. (b) Isolated NMDA receptormediated EPSPs recorded in the presence of CNQX and bicuculline are also suppressed by a high concentration of dopamine. Group data show a consistent suppression of the small isolated NMDA response.

$P<.001$; see Figure 4(b1)). Sulpiride also prevented the enhancement of paired-pulse facilitation induced by $50 \mu \mathrm{M}$ dopamine (see Figure 4(b2)). Although this indicates that the dopaminergic suppression of EPSPs is largely dependent upon activation of $\mathrm{D}_{2}$-like receptors, the suppression of responses in the presence of sulpiride was close to statistical significance $\left(t_{4}=2.65, P=.06\right)$, suggesting that a non$\mathrm{D}_{2}$ receptor-mediated mechanism mediates the residual suppression.

\subsection{Dopaminergic suppression of IPSPS}

Biphasic IPSPs were recorded from fan cells held near action potential threshold ( -51 to $-48 \mathrm{mV}$ ) and exposed to either $1 \mathrm{mM}$ kynurenic acid or a combination of $50 \mu \mathrm{M}$ APV and $20 \mu \mathrm{M}$ CNQX to block ionotropic glutamate transmission. A concentration of $50 \mu \mathrm{M}$ dopamine suppressed both the early $\mathrm{GABA}_{\mathrm{A}}$ - and late $\mathrm{GABA} \mathrm{B}_{\mathrm{B}}$-mediated components of the IPSP.
The early IPSP was reduced to $84.5 \pm 8.7 \%$ of baseline levels, and the late IPSP was reduced to $62.3 \pm 11.1 \%$ of baseline levels (see Figure 5(b); early, $t_{8}=2.41, P<.05, n=9$; late, $t_{7}=$ $2.46, P<.05, n=8)$. The dopaminergic suppression of GABA synapses indicates that the reduction of EPSPs by dopamine is unlikely to be due to increased GABAergic inhibition of fan cells.

\subsection{Modulation of intrinsic excitability}

Bath application of dopamine also hyperpolarized resting membrane potential and reduced the input resistance of fan cells. Membrane potential was increased from $-56.1 \pm 2.0$ to $-59.7 \pm 1.4 \mathrm{mV}$ (see Figure $6(\mathrm{a}) ; t_{8}=4.73, P<.001 ; n=$ 9 ), and peak input resistance was reduced from $90.3 \pm 7.6$ to $68.9 \pm 3.1 \mathrm{M} \Omega$ by $50 \mu \mathrm{M}$ dopamine (see Figure $6(\mathrm{~b}) ; t_{7}=$ $4.27, P<.01 ; n=8)$. Similar changes in membrane potential and input resistance were observed for $10 \mu \mathrm{M}$ dopamine (not shown) and have also been reported following application of high concentrations of dopamine in whole-cell recordings from medial entorhinal cortex stellate cells [30]. Changes were not due to the vehicle, because control cells and cells exposed to $1 \mu \mathrm{M}$ dopamine did not show a drop in input resistance or hyperpolarization of membrane potential.

In layer $\mathrm{V}$ entorhinal cortex cells dopamine causes a reduction in excitability and a drop in input resistance through an increase in the hyperpolarization-activated current $I_{\mathrm{h}}$ [32], and changes in $I_{\mathrm{h}}$ were therefore assessed in layer II fan cells. However, dopamine did not significantly affect the amount of inward rectification, and the rectification ratio remained stable (see Figure 6(d); $1.09 \pm 0.02$ in ACSF and in $50 \mu \mathrm{M}$ dopamine, $\left.t_{7}=0.00, P=1.00\right)$.

Dopamine suppressed the excitability of fan cells, and application of 10 and $50 \mu \mathrm{M}$ dopamine reduced the number of action potentials evoked by brief 500 milliseconds depolarizing current pulses (see Figure 7). The number of spikes was reduced from $4.1 \pm 0.1$ to $2.8 \pm 0.5$ spikes by $10 \mu \mathrm{M}$ dopamine (see Figure $7(\mathrm{~b}) ; t_{17}=2.54, P<.05 ; n=$ 18). A higher $50 \mu \mathrm{M}$ concentration of dopamine caused a similar reduction in the number of spikes (from $3.9 \pm 0.2$ to $2.8 \pm 0.6)$ that was not statistically significant $\left(t_{8}=1.82\right.$, $P=.11 ; n=9)$. The reduction in spiking could result in part from reduced input resistance, but it was not due to membrane hyperpolarization because cells were tested at the same membrane potential both before and after dopamine application.

The drop in input resistance induced by $50 \mu \mathrm{M}$ dopamine was blocked by coapplication of the $\mathrm{D}_{1}$ receptor antagonist SCH23390 (and there was actually a very small but reliable increase in $R_{\text {in }}$ in 4 of 5 cells; $t_{4}=2.60, P=.06$; see Figure 8(a)). The drop in input resistance was not affected by coapplication of the $\mathrm{D}_{2}$ receptor antagonist sulpiride $\left(t_{4}\right.$ $=9.71, P<.001 ; n=5$; Figure $8(\mathrm{~b}))$. The reduction in input resistance induced by dopamine is therefore dependent on activation of $\mathrm{D}_{1}$, but not $\mathrm{D}_{2}$, receptors.

The conductances that mediated the reduced input resistance were investigated using blockers of $\mathrm{Na}^{+}$and $\mathrm{K}^{+}$ channels. The $\mathrm{Na}^{+}$channel blocker TTX was used to verify that reductions in input resistance were not due to an 

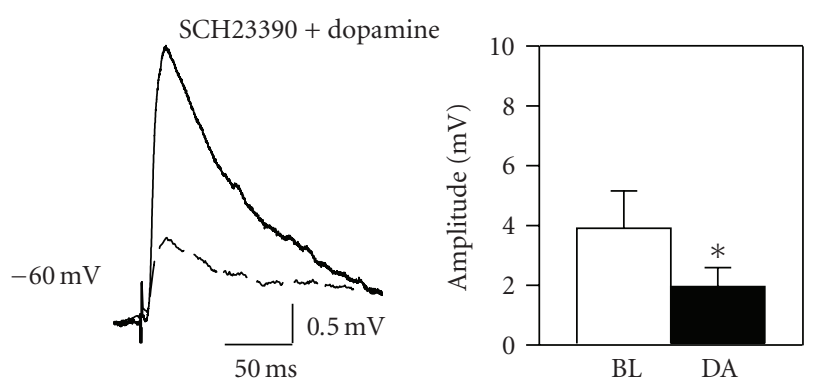

(a)
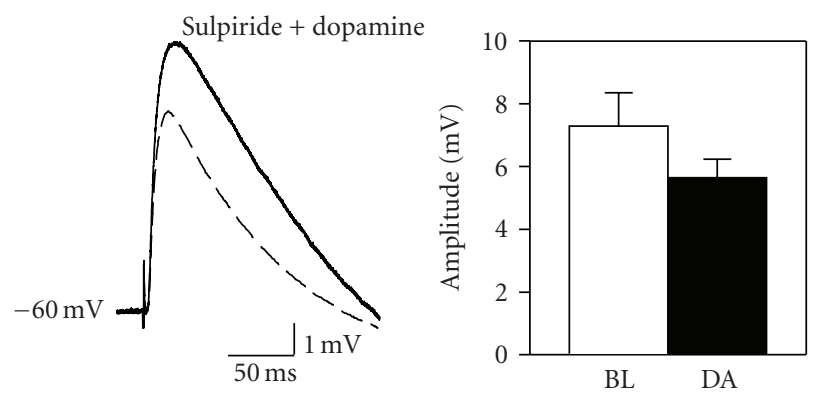

(b1)

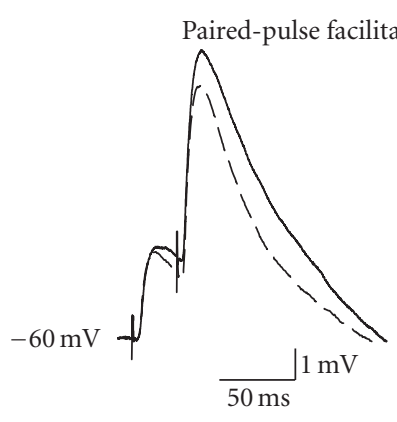

$-\mathrm{BL}$

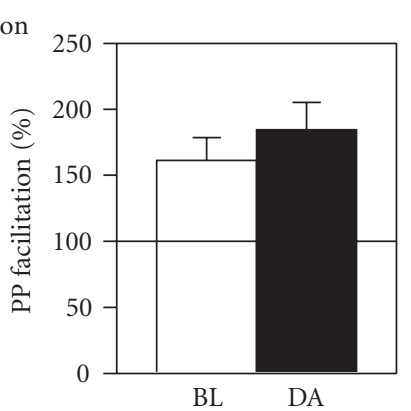

(b2)

FIGURE 4: Dopamine suppresses isolated AMPA-mediated EPSPs via a $\mathrm{D}_{2}$ receptor-dependent mechanism. (a) Coapplication of the $\mathrm{D}_{1}$ receptor antagonist SCH23390 $(50 \mu \mathrm{M})$ did not prevent the dopamine-induced reduction in EPSP amplitude. (b) However, coapplication of the $\mathrm{D}_{2}$ receptor antagonist sulpiride $(50 \mu \mathrm{M})$ significantly attenuated the dopaminergic suppression of EPSPs. Sulpiride also prevented the enhancement of paired-pulse facilitation induced by dopamine (b2).

increase in action potential-dependent synaptic inputs to fan cells, or due to an altered $\mathrm{Na}^{+}$conductance. Blockade of $\mathrm{Na}^{+}$channels with TTX did not prevent the drop in input resistance induced by dopamine (see Figure 9(a); peak, $t_{4}$ = 6.02, $P<.01$; steady-state, $t_{4}=8.21, P<.01 ; n=$ $5)$. It has been suggested that the reduced input resistance
GABA IPSP

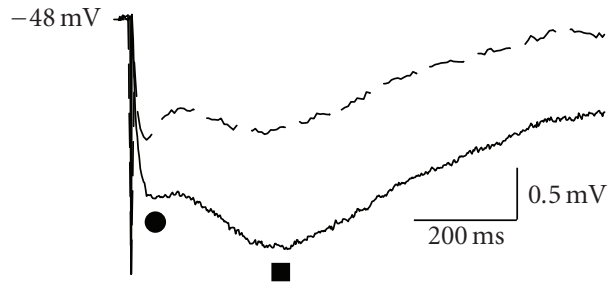

$-\mathrm{BL}$

$--\mathrm{DA}$

(a)

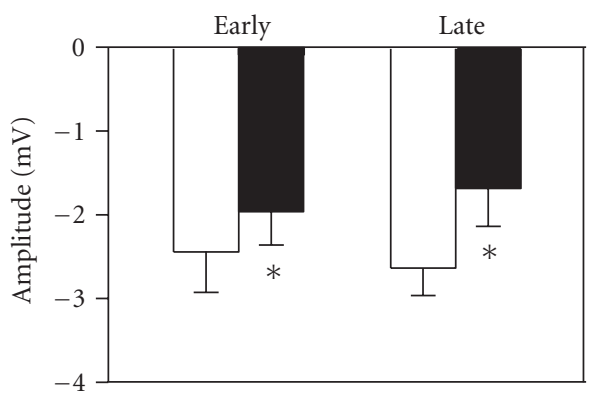

$\mathrm{BL}$

DA

(b)

FIGURE 5: Dopamine suppresses both the fast and slow components of the mixed monosynaptic IPSP in fan cells. (a) GABA-mediated IPSPs were isolated pharmacologically with ionotropic glutamate receptor blockers and recorded at membrane potentials just below action potential threshold. Both the early (circle) and late (square) components of the biphasic IPSP were suppressed by $50 \mu \mathrm{M}$ dopamine (DA). (b) Group data reflect a significant suppression of both the early and late IPSPs.

induced by dopamine in medial entorhinal cortex stellate cells might be mediated by an increased $\mathrm{K}^{+}$conductance [30], and we therefore assessed the effects of dopamine on input resistance in the presence of the $\mathrm{K}^{+}$channel blocker TEA ( $30 \mathrm{mM} ; n=5$ ). Coapplication of TEA blocked the reduction in input resistance induced by dopamine (see Figure 9(b)), indicating that the $\mathrm{D}_{1}$ receptor-dependent reduction in input resistance involves an increased $\mathrm{K}^{+}$ conductance. The increased $\mathrm{K}^{+}$conductance is likely to contribute to the hyperpolarization of membrane potential induced by dopamine, and may also account for the reduced excitability of fan cells (see Figure 7 ). The reduced input resistance may also contribute to the dopamine-induced suppression of EPSPs; the $\mathrm{D}_{2}$ receptor blocker sulpiride did not fully prevent the suppression of AMPA-mediated EPSPs (see Figure 4(b1)), and the $\mathrm{D}_{1}$ receptor-mediated reduction in input resistance could contribute to part of the EPSP suppression. 


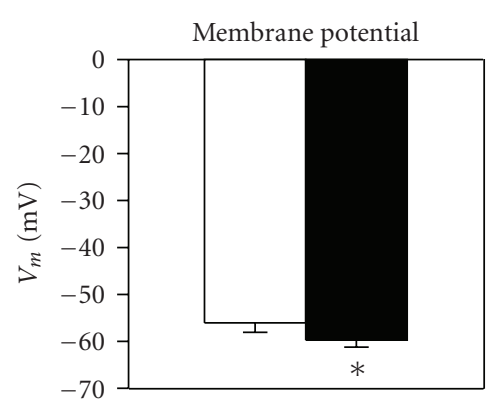

ACSF

DA

(a)

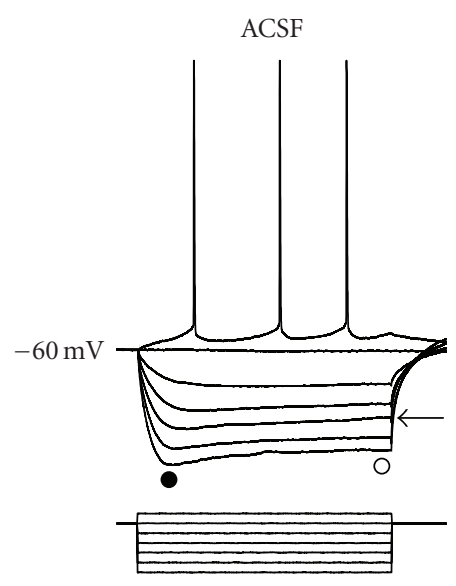

(c1)

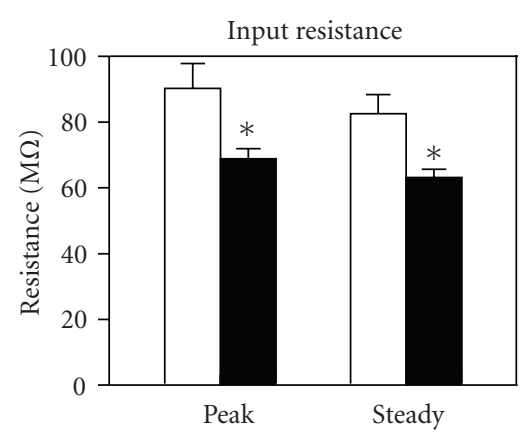

ACSF

DA

(b)

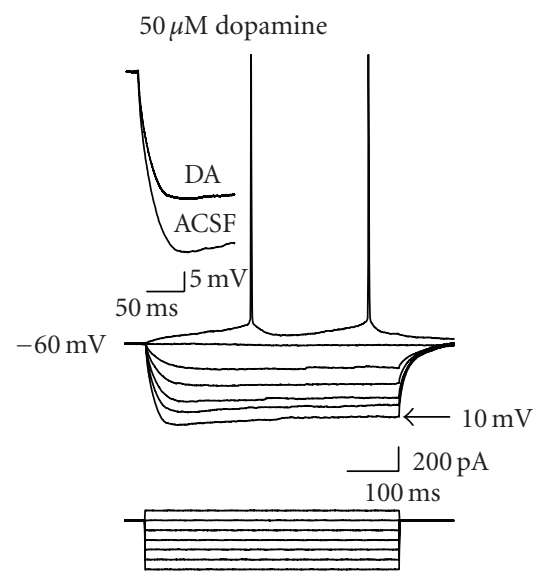

(c2)
ACSF

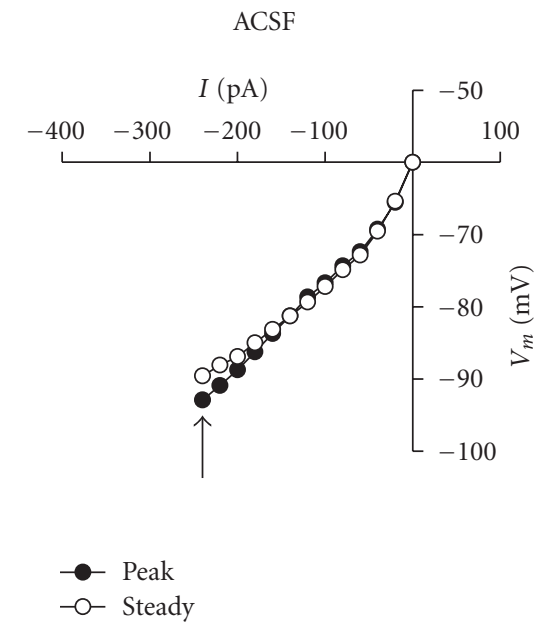

$(\mathrm{d} 1)$
$50 \mu \mathrm{M}$ dopamine

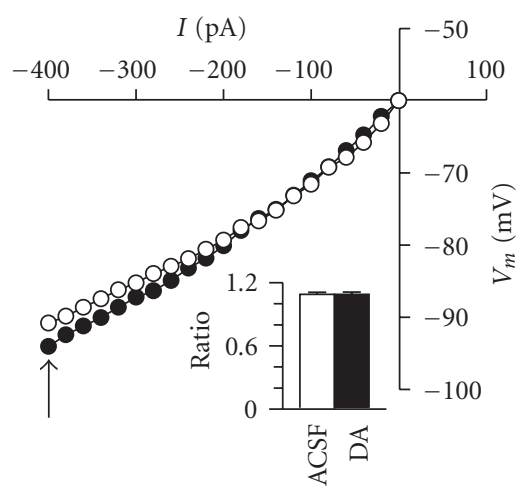

- Peak
- - Stead

(d2)

FiguRE 6: Dopamine hyperpolarizes membrane potential and reduces the input resistance of layer II fan cells. (a) Membrane potential was shifted to more hyperpolarized potentials by dopamine $\left({ }^{*}, P<.001\right)$. (b) Dopamine also reduced both peak and steady-state input resistance $(*, P<.01)$. (c) Voltage responses to applied current steps before (c1) and after (c2) bath application of $50 \mu \mathrm{M}$ dopamine in a representative cell. Action potentials are truncated. Circles in $(\mathrm{c} 1)$ indicate the latencies at which peak and steady-state input resistance were measured. Inset traces in (c2) compare the initial voltage deflection to a $-200 \mathrm{pA}$ current step before and after application of dopamine. Arrows indicate voltage responses before and after dopamine that were similar in amplitude and which allow comparison of the magnitude of the inward rectification. Note also the reduced input resistance across the entire range of hyperpolarizing current pulses. (d) Currentvoltage plots show peak and steady-state responses to current steps of increasing size. Arrows indicate points at which a comparable degree of inward rectification was observed during hyperpolarization to similar voltages before and after dopamine application. 


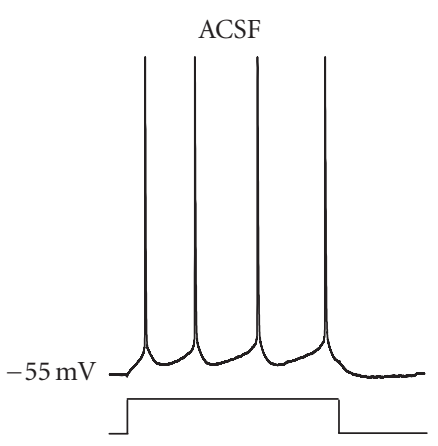

(a1)

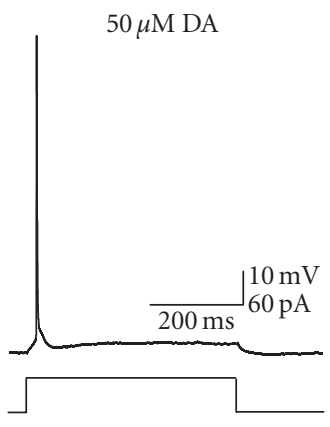

(a2)

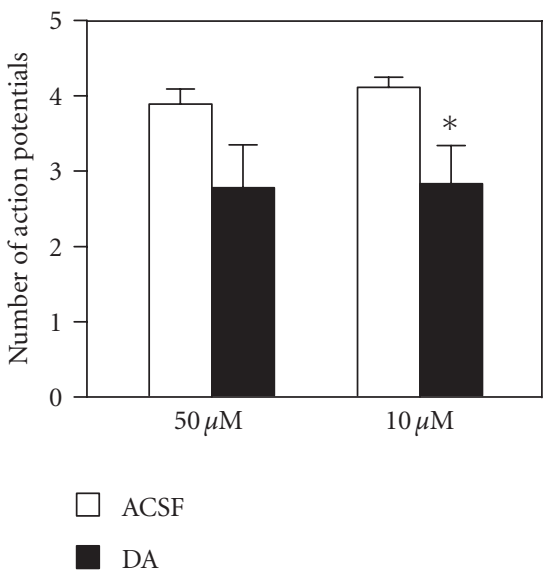

(b)

FIgURE 7: The number of action potentials elicited by positive current steps is reduced by dopamine. (a) Traces show action potentials generated in response to 500 milliseconds duration, $60 \mathrm{pA}$ current steps before and after application of $50 \mu \mathrm{M}$ dopamine. The example shown reflects a particularly large reduction to only one action potential following application of dopamine. Action potentials are truncated. (b) Group data show a reduction in firing for both the 10 and $50 \mu \mathrm{M}$ conditions but only the reduction in the $10 \mu \mathrm{M}$ condition was significant.

\section{DISCUSSION}

We show here that dopamine has powerful suppressive effects on glutamate-mediated synaptic transmission in layer II fan cells ofthe lateral entorhinal cortex. Our findings suggest that the suppression of EPSPs involves the combined actions of a $\mathrm{D}_{2}$ receptor-mediated reduction in neurotransmitter release and a $\mathrm{D}_{1}$ receptor-mediated increase in a $\mathrm{K}^{+}$conductance that reduces cellular input resistance. Previously, we found that field EPSPs were enhanced by low concentrations of dopamine in vitro, and by blocking dopamine reuptake in awake animals [29]. This suggested that moderate increases in dopamine release might facilitate synaptic responses in the entorhinal cortex, and enhance transmission of sensory information to the rest of the hippocampal formation. Here, we have replicated the synaptic facilitation with a low $1 \mu \mathrm{M}$ concentration of dopamine and have also shown that high concentrations of dopamine induce a strong and reversible suppression of intracellular EPSPs. Similar suppression effects have been observed in the medial entorhinal cortex [30,31] and prefrontal cortex [22, 23, 50, 51] using comparable doses of dopamine.

\subsection{Suppression of glutamate release}

The suppression of EPSPs by high concentrations of dopamine was found to be largely dependent on $\mathrm{D}_{2}$ receptors since coapplication of the $\mathrm{D}_{2}$ receptor antagonist sulpiride blocked most of the reduction. Dopamine also enhanced paired-pulse facilitation which suggests that the suppression of EPSPs resulted from a reduction in presynaptic glutamate release $[47,49]$. The suppression of both AMPA- and NMDA-mediated components of the synaptic response is also consistent with reduced transmitter release. Although similar reductions in EPSPs have been shown in stellate cells of the medial entorhinal cortex, the suppression was dependent on $D_{1}$, and not $D_{2}$, receptor activation [30]. However, Stenkamp et al. (1998) showed a reduction in synaptic responses in layer III of the medial entorhinal cortex through activation of both $\mathrm{D}_{1}$ and $\mathrm{D}_{2}$ receptors, and results of paired-pulse tests in their study suggested that the suppression was also mediated by reduced glutamate release.

Dopamine has been shown to suppress AMPA-mediated synaptic responses in the prefrontal cortex through a $D_{1}$ receptor-mediated suppression of transmitter release [2224]. Strong activation of $D_{1}$ receptors can also suppress synaptic responses through a retrograde signaling cascade. Weak $D_{1}$ receptor activation can enhance NMDA responses, but stronger $D_{1}$ receptor activation can lead to more intense NMDA receptor activation and the release of adenosine that suppresses transmitter release by acting on presynaptic $\mathrm{A}_{1}$ receptors that suppress voltage-gated $\mathrm{Ca}^{2+}$ channels $[28,52,53]$. In the striatum, activation of presynaptic $\mathrm{D}_{2}$ receptors suppresses $\mathrm{N}$-type $\mathrm{Ca}^{2+}$ currents and inhibits acetylcholine release from striatal cholinergic interneurons [54]. $\mathrm{D}_{2}$ receptors have also been linked to a suppression of responses in the parabrachial nucleus [55], ventral tegmental area [56], and striatum $[57,58]$ via a $\mathrm{D}_{2}$-mediated reduction in glutamate release. A similar $\mathrm{D}_{2}$-mediated mechanism underlies the suppression of GABA release from striatal inhibitory cells onto cholinergic interneurons [59]. Similar mechanisms may mediate the dopaminergic suppression of glutamate release in the entorhinal cortex.

The dopaminergic suppression of EPSPs observed here cannot be explained by increased transmission at GABA synapses because we found that dopamine reduced monosynaptic $\mathrm{GABA}_{\mathrm{A}}$ and $\mathrm{GABA}_{\mathrm{B}}$ IPSPs. The suppression is also unlikely to be due to increased activation of feedback inhibition [60] because dopamine reduced both glutamatergic 


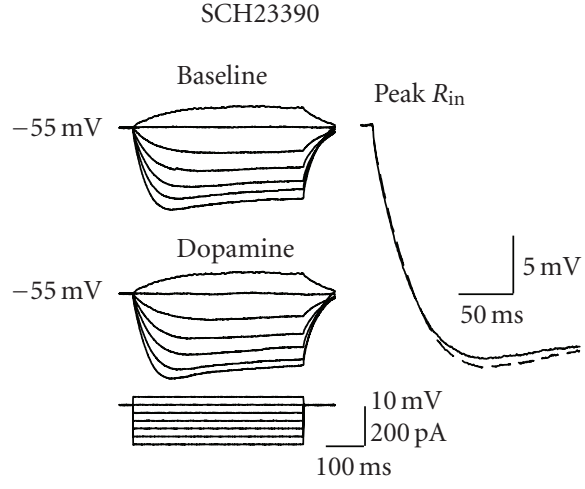

$-\mathrm{BL}$
$--\mathrm{DA}$

(a1)

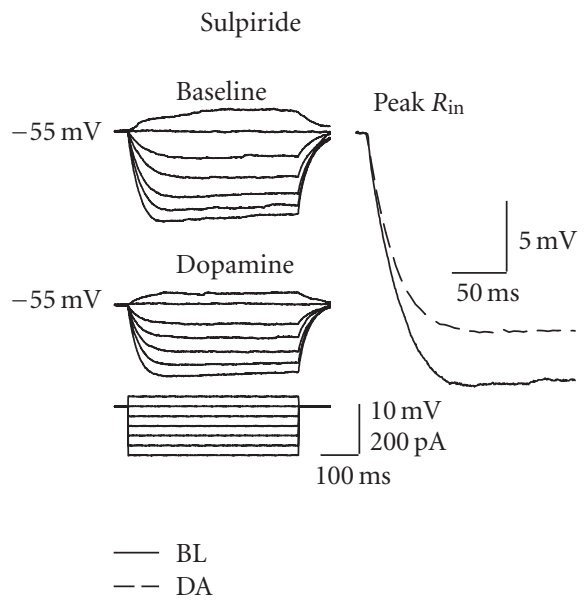

(b1)

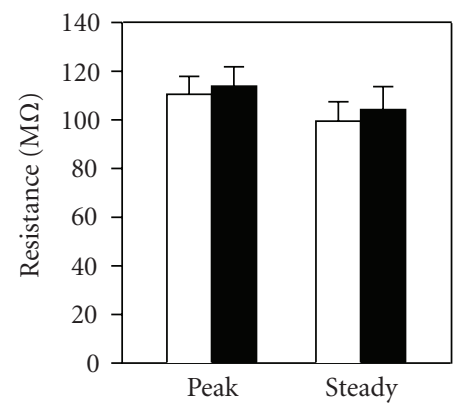

$\square \mathrm{BL}$

DA

(a2)

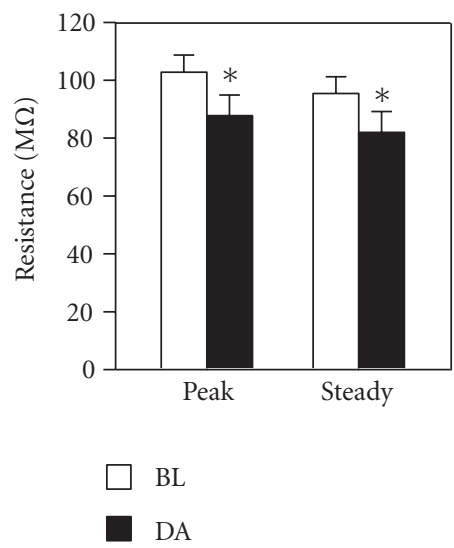

(b2)

FIGURE 8: Blockade of $\mathrm{D}_{1}$, but not $\mathrm{D}_{2}$, receptors prevents the dopamine-induced reduction in input resistance. (a) Bath-application of the $\mathrm{D}_{1}$ receptor antagonist $\mathrm{SCH} 23390(50 \mu \mathrm{M})$ prevented the reduction in input resistance induced by $50 \mu \mathrm{M}$ dopamine. Traces at left show voltage responses to a series of current steps during baseline recordings in SCH23390 and during subsequent dopamine application. Traces at right compare the initial voltage responses to $-200 \mathrm{pA}$ steps before and after dopamine application. Note that input resistance is unchanged when $\mathrm{D}_{1}$ receptors are blocked. (b) The $\mathrm{D}_{2}$ receptor blocker sulpiride $(50 \mu \mathrm{M})$ does not prevent changes in input resistance induced by dopamine (*, $P<.001)$.

transmission and the number of spikes in fan cells (see Figure 7). The suppression of monosynaptic IPSPs that we observed may have resulted from a $\mathrm{D}_{2}$-mediated reduction in GABA release $[59,61]$ and reduced input resistance in fan cells could also have contributed. These possibilities are consistent with the parallel reductions observed in $\mathrm{GABA}_{\mathrm{A}}$ and $\mathrm{GABA}_{\mathrm{B}}$ IPSPs. Recordings of spontaneous and/or miniature IPSCs would be useful to determine the mechanisms of the reduced IPSPs.

\subsection{Modulation of intrinsic excitability}

In addition to the $\mathrm{D}_{2}$-mediated suppression of transmitter release, high concentrations of dopamine also appear to sup- press synaptic transmission through a $\mathrm{D}_{1}$-receptor dependent mechanism. Sulpiride did not completely block the suppression of EPSPs (see Figure 4(b1)), and a $\mathrm{D}_{1}$ receptordependent activation of a TEA-sensitive $\mathrm{K}^{+}$conductance appears to mediate the residual suppression via a reduction in input resistance. Blockade of synaptic transmission and voltage-gated $\mathrm{Na}^{+}$channels with TTX did not prevent the drop in input resistance induced by dopamine indicating that it is not due to increased spontaneous synaptic drive or to an increased $\mathrm{Na}^{+}$conductance. However, the broadly acting $\mathrm{K}^{+}$channel blocker TEA prevented the drop in input resistance, indicating that dopamine activates a $\mathrm{K}^{+}$ conductance. The drop in input resistance was also prevented by blockade of $\mathrm{D}_{1}$, but not $\mathrm{D}_{2}$, receptors, indicating that 


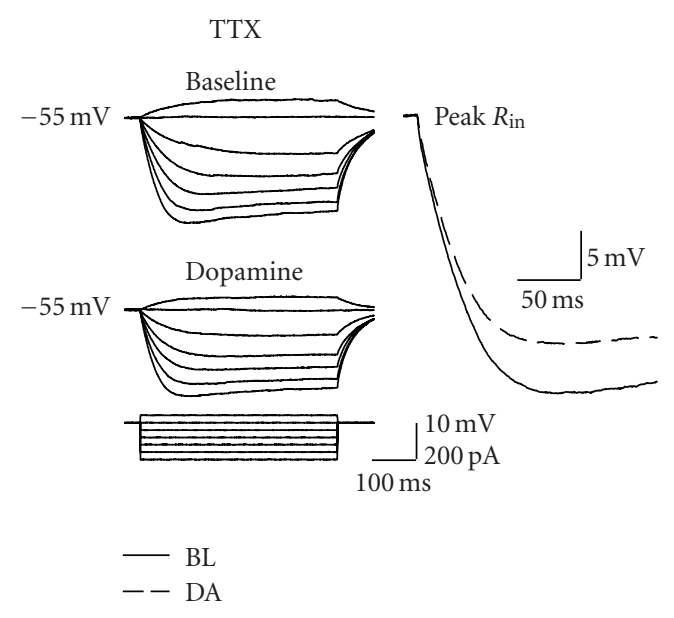

(a1)

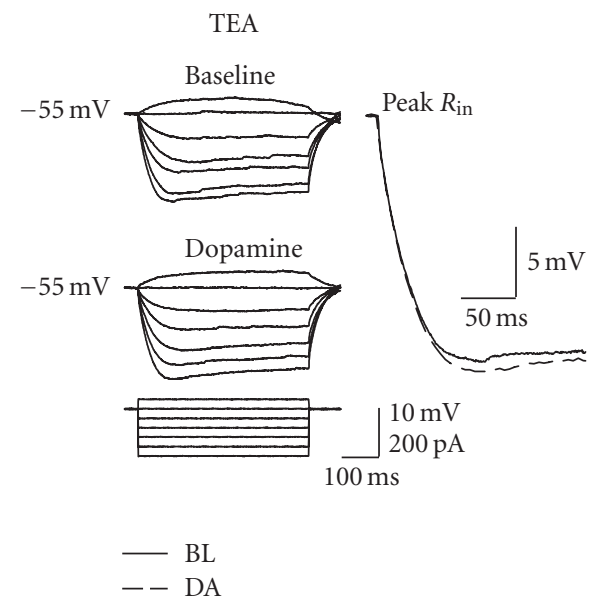

(b1)

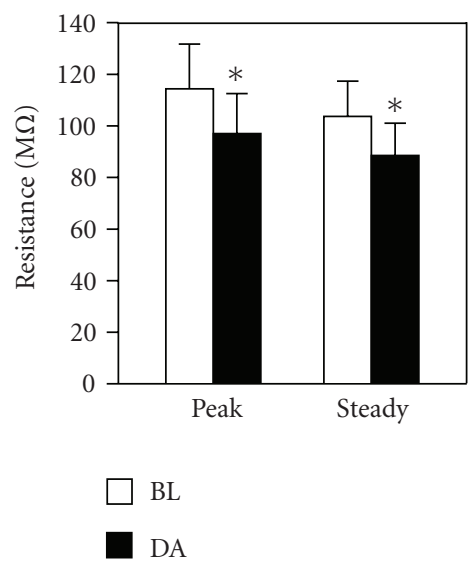

(a2)

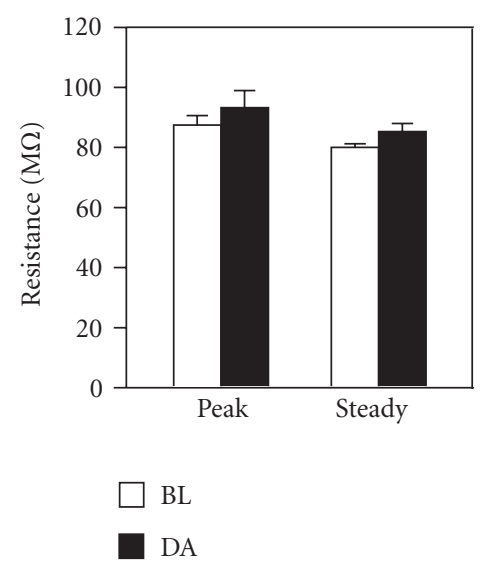

(b2)

FIGURE 9: Blocking potassium channels prevent the dopamine-induced reduction in input resistance. (a) Blockade of $\mathrm{Na}^{+}$channels with $0.5 \mu \mathrm{M}$ TTX does not prevent the reduction of peak or steady-state input resistance induced by $50 \mu \mathrm{M}$ dopamine $(*, P<.01)$. Conventions are as in Figure 8. (b) In contrast, coapplication of the $\mathrm{K}^{+}$channel blocker TEA $(30 \mathrm{mM})$ prevented the dopamine-induced reduction in input resistance.

dopamine activates $\mathrm{K}^{+}$channels via $\mathrm{D}_{1}$ receptors. High concentrations of dopamine also hyperpolarize membrane potential and reduce input resistance in stellate cells of the medial entorhinal cortex, and it was also suggested that these changes might be mediated by an increased $\mathrm{K}^{+}$conductance [30].

A large number of $\mathrm{K}^{+}$conductancesare affected by TEA, and it is therefore not clear which type(s) may be responsible for the drop in input resistance observed here. Background leak channels are insensitive to TEA [62] and are therefore not likely to contribute. Voltage-gated $\mathrm{K}^{+}$ currents are blocked by TEA, but dopamine in the prefrontal cortex tends to enhance neuronal excitability by suppressing these currents (see also $[43,63]$ ). Several reports in CA1 pyramidal cells have found that dopamine hyperpolarizes membrane potential, reduces input resistance, and increases afterhyperpolarizations through a $\mathrm{D}_{1}$-receptor mediated increase in $\mathrm{Ca}^{2+}$-activated $\mathrm{K}^{+}$currents $([64,65]$, see also [66]), but others have found an increase in the excitability of CA1 neurons due to a suppression of $\mathrm{Ca}^{2+}$-activated $\mathrm{K}^{+}$ currents (see also $[32,67,68]$ ). Here, there was no clear increase in afterhyperpolarizations, suggesting that $\mathrm{Ca}^{2+}$ dependent $\mathrm{K}^{+}$currents do not mediate the change in input resistance. Activation of $\mathrm{D}_{1}$ receptors can also have dosedependent effects on activation of inward rectifying $\mathrm{K}^{+}$ currents (IRKCs). In the prefrontal cortex, $\mathrm{D}_{1}$ receptor activation typically inhibits IRKC by direct effects of cAMP on IRK channels, but strong activation can increase IRKC via phosphorylation of the channels through elevated levels of PKA [69]. This could explain why a significant reduction in input resistance was observed here only at the higher concentrations of dopamine. Clearly, however, further experiments 
will be required to determine the nature of the $\mathrm{D}_{1}$ receptordependent $\mathrm{K}^{+}$conductance in fan cells.

We observed a decrease in fan cell firing during depolarizing current steps after dopamine, and the reduced spiking may reflect the drop in cellular input resistance. A surprising finding was that while the $\mathrm{D}_{1}$ receptor antagonist SCH23390 prevented the dopamine-induced reduction in input resistance it did not completely eliminate the reduction in the number of spikes, suggesting that reduced input resistance cannot entirely account for the reduction in spiking, and that other mechanisms may also contribute. $\mathrm{D}_{1}$ receptor activation can increase spiking in prefrontal neurons by enhancing the persistent $\mathrm{Na}^{+}$current $\left(I_{\mathrm{NaP}}\right)$ and suppressing a slowly-inactivating $\mathrm{K}^{+}$conductance [43, $70]$, but a suppression of spiking via a reduction in $I_{\mathrm{NaP}}$ has also been observed [71]. In layer $\mathrm{V}$ entorhinal cortex neurons, dopamine reduces input resistance and leads to a reduction of spiking though an increase in $I_{h}$ [32]. Here, there was no apparent change in $I_{\mathrm{h}}$ in fan cells, and action potential threshold and afterhyperpolarizations were not affected, suggesting that the underlying currents were not modified. Dopaminergic effects on $I_{\mathrm{NaP}}$ were not directly assessed in the present study, and the drop in input resistance could mask possible reductions in depolarizing responses to current injection related to $I_{\mathrm{NaP}}$. However, in tests in which SCH23390 prevented a change in input resistance, we found no reduction in the response to $+20 \mathrm{pA}$ pulses. This argues against a $\mathrm{D}_{1}$-mediated reduction in $I_{\mathrm{NaP}}$, but it is still possible that dopamine may reduce spiking via a $\mathrm{D}_{2}$ receptor-mediated reduction in $I_{\mathrm{NaP}}$ [71].

\section{CONCLUSIONS}

We have shown here that dopamine has concentrationdependent, bidirectional effects on glutamate-mediated synaptic transmission in principal cells of layer II of the lateral entorhinal cortex. The lateral entorhinal cortex receives a major input from the piriform cortex [5-7], and dopaminergic innervation of the superficial layers is likely to have a strong modulatory effect on olfactory processing. In the prefrontal cortex, moderate activation of dopaminergic inputs promotes workingmemory function, but excessive dopamine activation leads to a decrement in performance $[20,27]$. In the entorhinal cortex, moderate increases in dopamine concentration may enhance the salience of olfactory representations carried to the lateral entorhinal cortex (see Figure 1(c); see also 29), but large increases in dopamine associated with drug effects or acute stress [27] may dampen synaptic inputs to the superficial layers and suppress working memory function [72-74] or induction of lasting synaptic plasticity [75]. The dopaminergic suppression of synaptic transmission in layer II is also likely to inhibit the propagation of sensory information to the rest of the hippocampal formation such that only strong and synchronous inputs to the entorhinal region may be sufficient to activate entorhinal projection neurons.

\section{ACKNOWLEDGMENTS}

This research was funded by grants to Douglas A. Caruana and C. Andrew Chapman from the Natural Sciences and Engineering Research Council of Canada. C. Andrew Chapman is a member of the Center for Studies in Behavioral Neurobiology funded by the Fonds pour la Recherche en Santé du Québec.

\section{REFERENCES}

[1] L. R. Squire and S. M. Zola, "Structure and function of declarative and nondeclarative memory systems," Proceedings of the National Academy of Sciences of the United States of America, vol. 93, no. 24, pp. 13515-13522, 1996.

[2] P. Lavenex and D. G. Amaral, "Hippocampal-neocortical interaction: a hierarchy of associativity," Hippocampus, vol. 10, no. 4, pp. 420-430, 2000.

[3] R. Schwarcz and M. P. Witter, "Memory impairment in temporal lobe epilepsy: the role of entorhinal lesions," Epilepsy Research, vol. 50, no. 1-2, pp. 161-177, 2002.

[4] L. R. Squire, C. E. L. Stark, and R. E. Clark, "The medial temporal lobe," Annual Review of Neuroscience, vol. 27, pp. 279-306, 2004.

[5] R. D. Burwell, "The parahippocampal region: corticocortical connectivity," Annals of the New York Academy of Sciences, vol. 911, pp. 25-42, 2000.

[6] R. D. Burwell and D. G. Amaral, "Cortical afferents of the perirhinal, postrhinal, and entorhinal cortices of the rat," Journal of Comparative Neurology, vol. 398, no. 2, pp. 179-205, 1998.

[7] K. M. Kerr, K. L. Agster, S. C. Furtak, and R. D. Burwell, "Functional neuroanatomy of the parahippocampal region: the lateral and medial entorhinal areas," Hippocampus, vol. 17, no. 9, pp. 697-708, 2007.

[8] T. Hafting, M. Fyhn, S. Molden, M.-B. Moser, and E. I. Moser, "Microstructure of a spatial map in the entorhinal cortex," Nature, vol. 436, no. 7052, pp. 801-806, 2005.

[9] E. L. Hargreaves, G. Rao, I. Lee, and J. J. Knierim, "Major dissociation between medial and lateral entorhinal input to dorsal hippocampus," Science, vol. 308, no. 5729, pp. 17921794, 2005.

[10] T. V. Sewards and M. A. Sewards, "Input and output stations of the entorhinal cortex: superficial vs. deep layers or lateral vs. medial divisions?" Brain Research Reviews, vol. 42, no. 3, pp. 243-251, 2003.

[11] B. H. Bland and S. D. Oddie, "Theta band oscillation and synchrony in the hippocampal formation and associated structures: the case for its role in sensorimotor integration," Behavioural Brain Research, vol. 127, no. 1-2, pp. 119-136, 2001.

[12] C. R. Grünschlag, H. L. Haas, and D. R. Stevens, "5-HT inhibits lateral entorhinal cortical neurons of the rat in vitro by activation of potassium channel-coupled 5-HT(1A) receptors," Brain Research, vol. 770, no. 1-2, pp. 10-17, 1997.

[13] B. N. Hamam, M. Sinai, G. Poirier, and C. A. Chapman, "Cholinergic suppression of excitatory synaptic responses in layer II of the medial entorhinal cortex," Hippocampus, vol. 17, no. 2, pp. 103-113, 2006.

[14] L. Ma, M. H. Shalinsky, A. Alonso, and C. T. Dickson, "Effects of serotonin on the intrinsic membrane properties of layer II medial entorhinal cortex neurons," Hippocampus, vol. 17, no. 2, pp. 114-129, 2007. 
[15] D. Schmitz, T. Gloveli, R. M. Empson, A. Draguhn, and U. Heinemann, "Serotonin reduces synaptic excitation in the superficial medial entorhinal cortex of the rat via a presynaptic mechanism," Journal of Physiology, vol. 508, no. 1, pp. 119129, 1998.

[16] A. Björklund and O. Lindvall, "Dopamine-containing systems in the CNS," in Handbook of Chemical Neuroanatomy. Vol. 2, A. Björklund and T. Hökfelt, Eds., Classical Transmitters in the CNS, Part I, pp. 55-122, Elsevier, Amsterdam, The Netherlands, 1984.

[17] J. H. Fallon and S. E. Loughlin, "Monoamine innervation of cerebral cortex and a theory of the role of monoamines in cerebral cortex and basal ganglia," in Cerebral Cortex, E. G. Jones and A. Peters, Eds., pp. 41-127, Plenum, New York, NY, USA, 1987.

[18] R. D. Oades and G. M. Halliday, "Ventral tegmental (A10) system: neurobiology. 1. Anatomy and connectivity," Brain Research, vol. 434, no. 2, pp. 117-165, 1987.

[19] P. S. Goldman-Rakic, "The "psychic" neuron of the cerebral cortex," Annals of the New York Academy of Sciences, vol. 868, pp. 13-26, 1999.

[20] J. K. Seamans and C. R. Yang, "The principal features and mechanisms of dopamine modulation in the prefrontal cortex," Progress in Neurobiology, vol. 74, no. 1, pp. 1-58, 2004.

[21] A. G. Phillips, G. Vacca, and S. Ahn, "A top-down perspective on dopamine, motivation and memory," Pharmacology Biochemistry and Behavior, vol. 90, no. 2, pp. 236-249, 2008.

[22] W.-J. Gao, L. S. Krimer, and P. S. Goldman-Rakic, "Presynaptic regulation of recurrent excitation by $\mathrm{D}_{1}$ receptors in prefrontal circuits," Proceedings of the National Academy of Sciences of the United States of America, vol. 98, no. 1, pp. 295-300, 2001.

[23] D. Law-Tho, J. C. Hirsch, and F. Crepel, "Dopamine modulation of synaptic transmission in rat prefrontal cortex: an in vitro electrophysiological study," Neuroscience Research, vol. 21, no. 2, pp. 151-160, 1994.

[24] J. K. Seamans, D. Durstewitz, B. R. Christie, C. F. Stevens, and T. J. Sejnowski, "Dopamine D1/D5 receptor modulation of excitatory synaptic inputs to layer $\mathrm{V}$ prefrontal cortex neurons," Proceedings of the National Academy of Sciences of the United States of America, vol. 98, no. 1, pp. 301-306, 2001.

[25] S. Bandyopadhyay, C. Gonzalez-Islas, and J. J. Hablitz, "Dopamine enhances spatiotemporal spread of activity in rat prefrontal cortex," Journal of Neurophysiology, vol. 93, no. 2, pp. 864-872, 2005.

[26] C. Gonzalez-Islas and J. J. Hablitz, "Dopamine enhances EPSCs in layer II-III pyramidal neurons in rat prefrontal cortex," The Journal of Neuroscience, vol. 23, no. 3, pp. 867$875,2003$.

[27] A. F. T. Arnsten, "Catecholamine modulation of prefrontal cortical cognitive function," Trends in Cognitive Sciences, vol. 2, no. 11, pp. 436-447, 1998.

[28] C. R. Yang and L. Chen, "Targeting prefrontal cortical dopamine $\mathrm{D}_{1}$ and $\mathrm{N}$-methyl-D-aspartate receptor interactions in schizophrenia treatment," Neuroscientist, vol. 11, no. 5, pp. 452-470, 2005.

[29] D. A. Caruana, R. E. Sorge, J. Stewart, and C. A. Chapman, "Dopamine has bidirectional effects on synaptic responses to cortical inputs in layer II of the lateral entorhinal cortex," Journal of Neurophysiology, vol. 96, no. 6, pp. 3006-3015, 2006.

[30] E. Pralong and R. S. Jones, "Interactions of dopamine with glutamate- and GABA-mediated synaptic transmission in the rat entorhinal cortex in vitro," European Journal of Neuroscience, vol. 5, no. 6, pp. 760-767, 1993.
[31] K. Stenkamp, U. Heinemann, and D. Schmitz, "Dopamine suppresses stimulus-induced field potentials in layer III of rat medial entorhinal cortex," Neuroscience Letters, vol. 255, no. 2, pp. 119-121, 1998.

[32] J. A. Rosenkranz and D. Johnston, "Dopaminergic regulation of neuronal excitability through modulation of Ih in layer $\mathrm{V}$ entorhinal cortex," The Journal of Neuroscience, vol. 26, no. 12, pp. 3229-3244, 2006.

[33] S. D. Glasgow and C. A. Chapman, "Local generation of theta-frequency EEG activity in the parasubiculum," Journal of Neurophysiology, vol. 97, no. 6, pp. 3868-3879, 2007.

[34] D. Mueller, C. A. Chapman, and J. Stewart, "Amphetamine induces dendritic growth in ventral tegmental area dopaminergic neurons in vivo via basic fibroblast growth factor," Neuroscience, vol. 137, no. 3, pp. 727-735, 2006.

[35] G. Paxinos and C. Watson, The Rat Brain in Stereotaxic Coordinates, Academic Press, New York, NY, USA, 1998.

[36] T. W. Blackstad, "Commissural connections of the hippocampal region in the rat, with special reference to their mode of termination," Journal of Comparative Neurology, vol. 105, no. 3, pp. 417-537, 1956.

[37] A. A. Carboni and W. G. Lavelle, "Ultrastructural characterizations of olfactory pathway neurons in layer II of the entorhinal cortex in monkey," Acta Oto-Laryngologica, vol. 120, no. 3, pp. 424-431, 2000.

[38] O. Steward, "Topographic organization of the projections from the entorhinal area to the hippocampal formation of the rat," Journal of Comparative Neurology, vol. 167, no. 3, pp. 285$314,1976$.

[39] J. M. Wyss, "An autoradiographic study of the efferent connections of the entorhinal cortex in the rat," Journal of Comparative Neurology, vol. 199, no. 4, pp. 495-512, 1981.

[40] B. Tahvildari and A. Alonso, "Morphological and electrophysiological properties of lateral entorhinal cortex layers II and III principal neurons," Journal of Comparative Neurology, vol. 491, no. 2, pp. 123-140, 2005.

[41] X. Wang and N. A. Lambert, "Membrane properties of identified lateral and medial perforant pathway projection neurons," Neuroscience, vol. 117, no. 2, pp. 485-492, 2003.

[42] A. Alonso and R. Klink, "Differential electroresponsiveness of stellate and pyramidal-like cells of medial entorhinal cortex layer II," Journal of Neurophysiology, vol. 70, no. 1, pp. 128143, 1993.

[43] C. R. Yang and J. K. Seamans, "Dopamine $D_{1}$ receptor actions in layers V-VI rat prefrontal cortex neurons in vitro: modulation of dendritic-somatic signal integration," The Journal of Neuroscience, vol. 16, no. 5, pp. 1922-1935, 1996.

[44] R. Bouras and C. A. Chapman, "Long-term synaptic depression in the adult entorhinal cortex in vivo," Hippocampus, vol. 13, no. 7, pp. 780-790, 2003.

[45] D. A. Caruana and C. A. Chapman, "Stimulation of the parasubiculum modulates entorhinal cortex responses to piriform cortex inputs in vivo," Journal of Neurophysiology, vol. 92, no. 2, pp. 1226-1235, 2004.

[46] S. Kourrich and C. A. Chapman, "NMDA receptor-dependent long-term synaptic depression in the entorhinal cortex in vitro," Journal of Neurophysiology, vol. 89, no. 4, pp. 21122119, 2003.

[47] T. Manabe, D. J. Wyllie, D. J. Perkel, and R. A. Nicoll, "Modulation of synaptic transmission and long-term potentiation: effects on paired pulse facilitation and EPSC variance in the CA1 region of the hippocampus," Journal of Neurophysiology, vol. 70, no. 4, pp. 1451-1459, 1993. 
[48] R. S. Zucker, "Short-term synaptic plasticity," Annual Review of Neuroscience, vol. 12, pp. 13-31, 1989.

[49] R. S. Zucker and W. G. Regehr, "Short-term synaptic plasticity," Annual Review of Physiology, vol. 64, pp. 355-405, 2002.

[50] N. N. Urban, G. González-Burgos, D. A. Henze, D. A. Lewis, and G. Barrionuevo, "Selective reduction by dopamine of excitatory synaptic inputs to pyramidal neurons in primate prefrontal cortex," Journal of Physiology, vol. 539, no. 3, pp. 707-712, 2002.

[51] P. Zheng, X.-X. Zhang, B. S. Bunney, and W.-X. Shi, "Opposite modulation of cortical $\mathrm{N}$-methyl-D-aspartate receptormediated responses by low and high concentrations of dopamine," Neuroscience, vol. 91, no. 2, pp. 527-535, 1999.

[52] C. G. Craig, S. D. Temple, and T. D. White, "Is cyclic AMP involved in excitatory amino acid-evoked adenosine release from rat cortical slices?" European Journal of Pharmacology, vol. 269, no. 1, pp. 79-85, 1994.

[53] K. P. Scholz and R. J. Miller, "Presynaptic inhibition at excitatory hippocampal synapses: development and role of presynaptic $\mathrm{Ca}^{2+}$ channels," Journal of Neurophysiology, vol. 76, no. 1, pp. 39-46, 1996.

[54] Z. Yan, W.-J. Song, and D. J. Surmeier, " $\mathrm{D}_{2}$ dopamine receptors reduce $\mathrm{N}$-type $\mathrm{Ca}^{2+}$ currents in rat neostriatal cholinergic interneurons through a membrane-delimited, protein-kinaseC-insensitive pathway," Journal of Neurophysiology, vol. 77, no. 2, pp. 1003-1015, 1997.

[55] X. Chen, S. B. Kombian, J. A. Zidichouski, and Q. J. Pittman, "Dopamine depresses glutamatergic synaptic transmission in the rat parabrachial nucleus in vitro," Neuroscience, vol. 90, no. 2, pp. 457-468, 1999.

[56] E. Koga and T. Momiyama, "Presynaptic dopamine $\mathrm{D}_{2}$-like receptors inhibit excitatory transmission onto rat ventral tegmental dopaminergic neurones," Journal of Physiology, vol. 523, no. 1, pp. 163-173, 2000.

[57] K.-S. Hsu, C.-C. Huang, C.-H. Yang, and P.-W. Gean, "Presynaptic $\mathrm{D}_{2}$ dopaminergic receptors mediate inhibition of excitatory synaptic transmission in rat neostriatum," Brain Research, vol. 690, no. 2, pp. 264-268, 1995.

[58] M. S. Levine, L. I. Zhiwei, C. Cepeda, H. C. Cromwell, and K. L. Altemus, "Neuromodulatory actions of dopamine on synaptically-evoked neostriatal responses in slices," Synapse, vol. 24, no. 1, pp. 65-78, 1996.

[59] A. Pisani, P. Bonsi, D. Centonze, P. Calabresi, and G. Bernardi, "Activation of $\mathrm{D}_{2}$-like dopamine receptors reduces synaptic inputs to striatal cholinergic interneurons," The Journal of Neuroscience, vol. 20 RC69, no. 7, pp. 1-6, 2000.

[60] D. M. Finch, A. M. Tan, and M. Isokawa-Akesson, "Feedforward inhibition of the rat entorhinal cortex and subicular complex," The Journal of Neuroscience, vol. 8, no. 7, pp. 22132226, 1988.

[61] J. K. Seamans, N. Gorelova, D. Durstewitz, and C. R. Yang, "Bidirectional dopamine modulation of GABAergic inhibition in prefrontal cortical pyramidal neurons," The Journal of Neuroscience, vol. 21, no. 10, pp. 3628-3638, 2001.

[62] F. Lesage, "Pharmacology of neuronal background potassium channels," Neuropharmacology, vol. 44, no. 1, pp. 1-7, 2003.

[63] Y. Dong and F. J. White, "Dopamine $\mathrm{D}_{1}$-class receptors selectively modulate a slowly inactivating potassium current in rat medial prefrontal cortex pyramidal neurons," The Journal of Neuroscience, vol. 23, no. 7, pp. 2686-2695, 2003.

[64] L. S. Benardo and D. A. Prince, "Dopamine modulates a $\mathrm{Ca}^{2+}$ activated potassium conductance in mammalian hippocampal pyramidal cells," Nature, vol. 297, no. 5861, pp. 76-79, 1982.
[65] N. Berretta, F. Berton, R. Bianchi, M. Capogna, W. Francesconi, and M. Brunelli, "Effects of dopamine, D-1 and D-2 dopaminergic agonists on the excitability of hippocampal CA1 pyramidal cells in guinea pig," Experimental Brain Research, vol. 83, no. 1, pp. 124-130, 1990.

[66] S. Hernández-López, J. Bargas, A. Reyes, and E. Galarraga, "Dopamine modulates the afterhyperpolarization in neostriatal neurones," NeuroReport, vol. 7, no. 2, pp. 454-456, 1996.

[67] R. C. Malenka and R. A. Nicoll, "Dopamine decreases the calcium-activated afterhyperpolarization in hippocampal CA1 pyramidal cells," Brain Research, vol. 379, no. 2, pp. 210215, 1986.

[68] P. Pedarzani and J. F. Storm, "Dopamine modulates the slow $\mathrm{Ca}(2+)$-activated $\mathrm{K}^{+}$current IAHP via cyclic AMPdependent protein kinase in hippocampal neurons," Journal of Neurophysiology, vol. 74, no. 6, pp. 2749-2753, 1995.

[69] Y. Dong, D. Cooper, F. Nasif, X.-T. Hu, and F. J. White, "Dopamine modulates inwardly rectifying potassium currents in medial prefrontal cortex pyramidal neurons," The Journal of Neuroscience, vol. 24, no. 12, pp. 3077-3085, 2004.

[70] N. A. Gorelova and C. R. Yang, "Dopamine D1/D5 receptor activation modulates a persistent sodium current in rat prefrontal cortical neurons in vitro," Journal of Neurophysiology, vol. 84 , no. 1 , pp. 75-87, 2000.

[71] E. Geijo-Barrientos and C. Pastore, "The effects of dopamine on the subthreshold electrophysiological responses of rat prefrontal cortex neurons in vitro," European Journal of Neuroscience, vol. 7, no. 3, pp. 358-366, 1995.

[72] J. McGaughy, R. A. Koene, H. Eichenbaum, and M. E. Hasselmo, "Cholinergic deafferentation of the entorhinal cortex in rats impairs encoding of novel but not familiar stimuli in a delayed nonmatch-to-sample task," The Journal of Neuroscience, vol. 25, no. 44, pp. 10273-10281, 2005.

[73] B. Tahvildari, E. Fransén, A. A. Alonso, and M. E. Hasselmo, "Switching between "On" and "Off" states of persistent activity in lateral entorhinal layer III neurons," Hippocampus, vol. 17, no. 4, pp. 257-263, 2007.

[74] B. J. Young, T. Otto, G. D. Fox, and H. Eichenbaum, "Memory representation within the parahippocampal region," The Journal of Neuroscience, vol. 17, no. 13, pp. 5183-5195, 1997.

[75] D. A. Caruana, S. J. Reed, D. J. Sliz, and C. A. Chapman, "Inhibiting dopamine reuptake blocks the induction of longterm potentiation and depression in the lateral entorhinal cortex of awake rats," Neuroscience Letters, vol. 426, no. 1, pp. 6-11, 2007. 

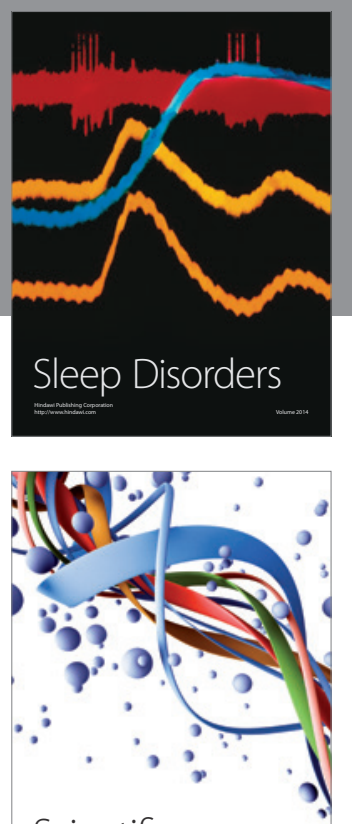

Scientifica
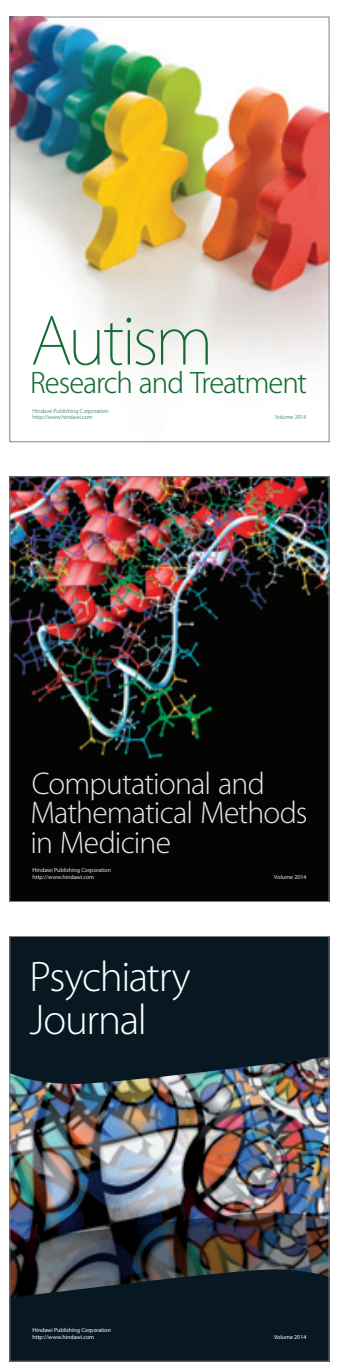
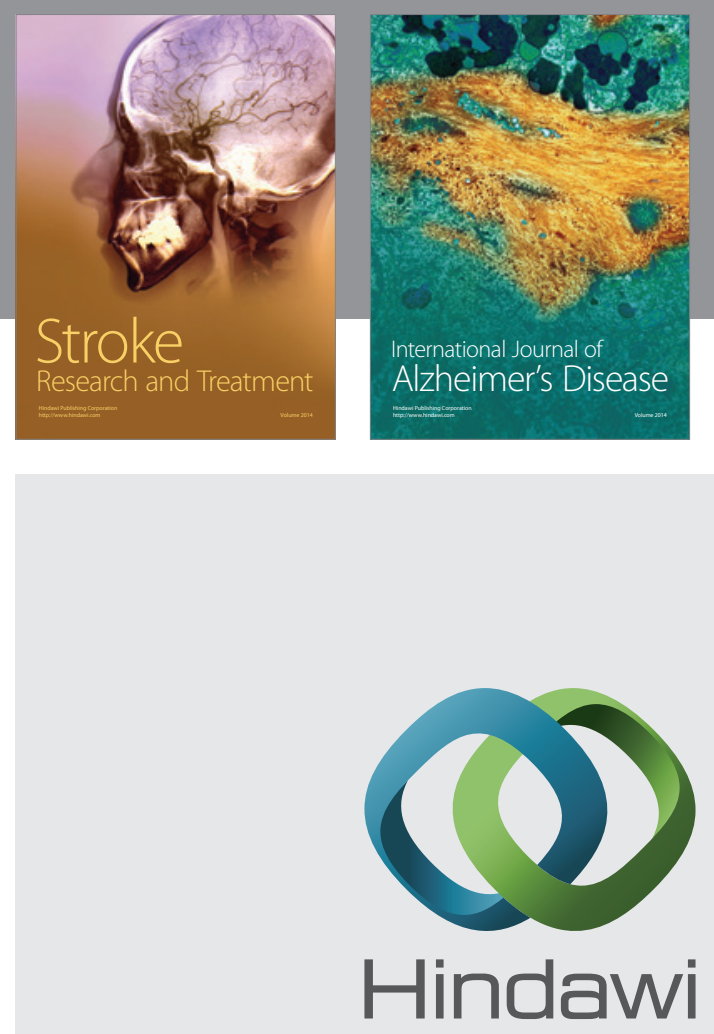

Submit your manuscripts at

http://www.hindawi.com
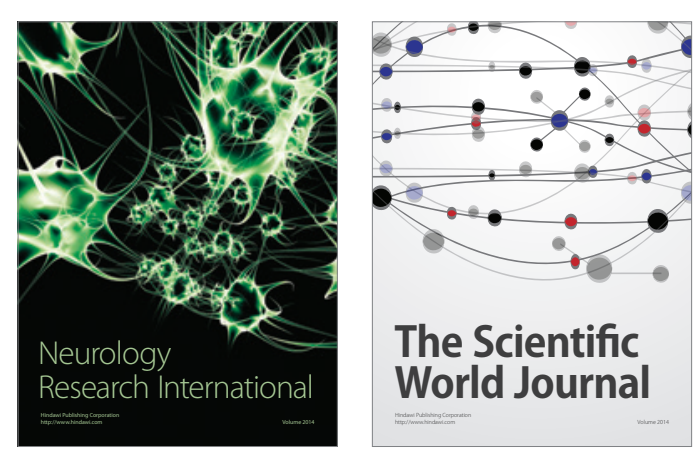

The Scientific World Journal

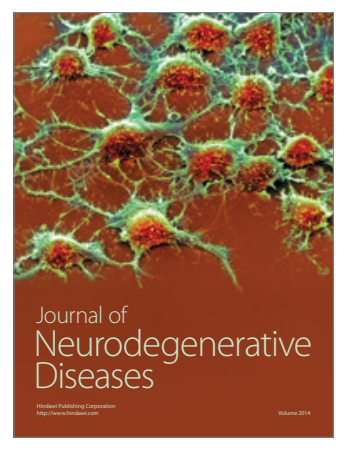

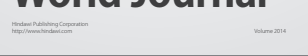

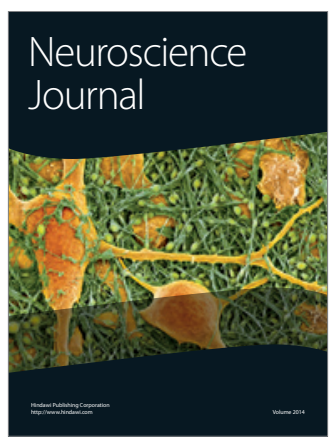

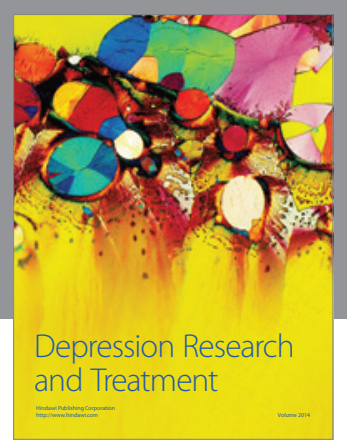
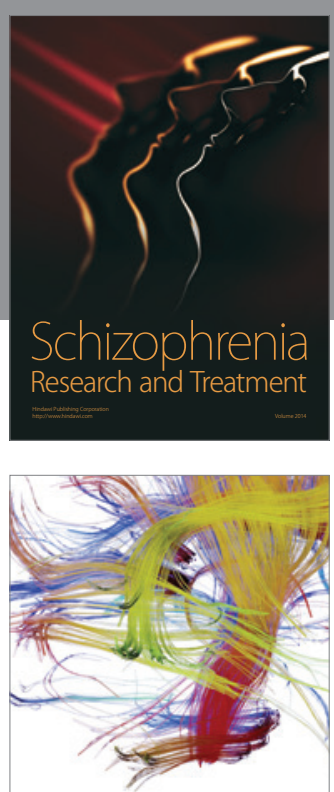

Brain Science

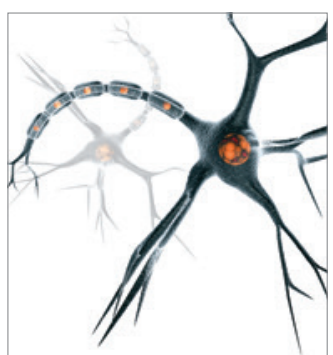

Neural Plasticity
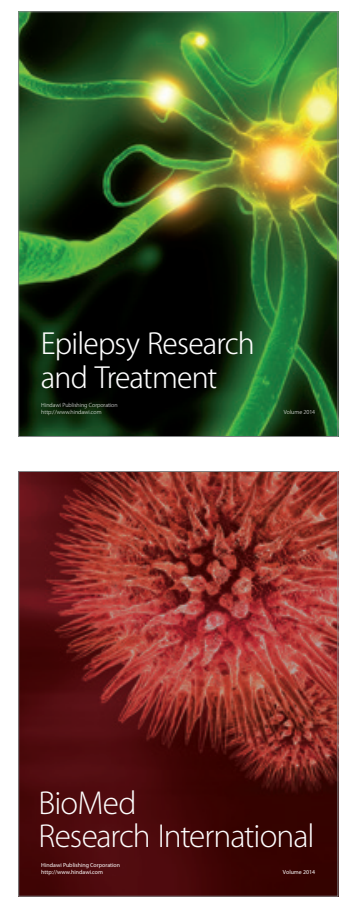

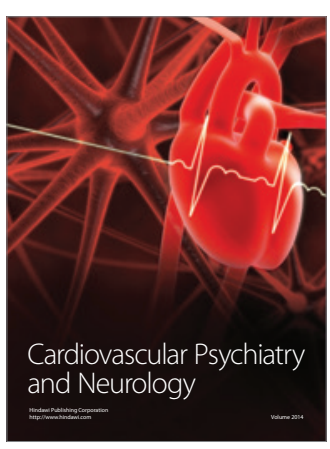

Parkinson's

Disease
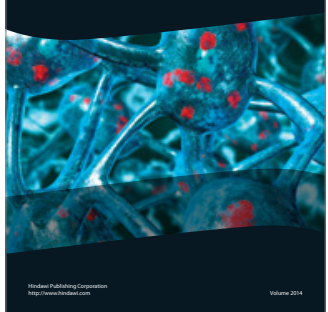